\title{
A FINANCING MODEL WITH REBATE CONTRACT IN A CAPITAL-CONSTRAINED SUPPLY CHAIN
}

\author{
JIZHOU ZHAN*
}

\begin{abstract}
In a two-level supply chain that includes one supplier and one capital-constrained retailer, this paper investigates a new bank financing model (Model N), in which, the supplier requires the retailer to order a quantity that is not less than a specified minimum ordering quantity (MOQ), rebates the per unit excess that sells over the MOQ, and promises to provide a partial warranty for the bank credit risk if the revenue is below the bankruptcy level of the retailer with the MOQ. This study shows that retailer's optimal order quantity increases with MOQ level and decreases with rebate rate, while supplier's optimal wholesale price shows an opposite tendency. Compared to the traditional bank financing model (Model $\mathrm{T}$ ), the model $\mathrm{N}$ with an appropriate rebate contract will result in a larger order quantity of retailer. Furthermore, model $\mathrm{N}$ would benefit the entire supply chain and a Pareto zone of MOQ (or rebate rate) exists, in which, model $\mathrm{N}$ outperforms model $\mathrm{T}$ for each player. The numerical experiments are performed to illustrate that with increasing the marginal production cost of supplier, the MOQ level is decreasing while rebate rate is increasing in the Pareto zone.
\end{abstract}

Mathematics Subject Classification. 90B06.

Received May 17, 2019. Accepted February 19, 2020.

\section{INTRODUCTION}

With the development of economic globalization, most firms often commit the constraints of capital and are not able to purchase or produce the quantity what they desired. Especially, the set-up firms or small and middle size enterprises (SME) are more easy to be capital-constrained. Obviously, the capital constraints could impact the firm's and even the entire supply chain's profits. Usually, the capital-constrained firms could raise operations capital from external banks by bank credit channel. However, most firms are not able to provide the required assets as collateral, or have the low scores of creditworthiness. And it should be very difficult for these firms to borrow capital from the banks [37]. The reason behind is that the bank has the poor information on the retailer's operations.

To solve the problem of capital-constrained retailers, several big manufacturers create some innovation models of supply chain finance. For example, some big companies have established the Finance Service Institutions (FSI), an internal/shadow bank who can lend the capital to the retailers. As a branch of big company, FSI has the information advantage on supply chain operations, and has a higher ability on reducing credit risk of retailer,

Keywords. Capital-constrained retailer, financing service, bank credit, rebate contract, supply chain finance.

School of Business, Nanjing Audit University, Nanjing 211815, P.R. China.

* Corresponding author: jzzhan@aliyun.com 
compared to the banks, it is able to monitor the retailers' operations or liquidate the left assets of defaulted retailers more effectively.

Consequently, the FSI usually could provide its own parent company's customers (e.g., retailers) with tailored supply chain finance service. For instance, the FSI of Siemens Electrical Apparatus Ltd., found in $1997^{1}$, hold an average annual 12 billion operation fund, provided Siemens' customers with financing service, and contributed a steady profit to Simens Group. According to Small Business Administration (SBA) in America, more than $16 \%$ SMEs have been financed from FSI in 2013, and FSI is the second finance channel for start-up firms ${ }^{2}$. In the emerging market, some big companies also hold their own FSIs. For example, East Auto Industry of China set up the first FSI in 1987, since that the number of FSI reached to 192 in China until $2014^{3}$. Similarly, TCL, Haier, Gree, Shanghai Auto Group, Beijing Auto Group, etc., also build FSIs to the customers, and create much more value to their supply chains.

This paper is motivated by the practice of FSI from Haier Group, a Chinese famous household electric manufacturer who increased its profit from RMB 1.83 billion in 2007 to RMB 10.8 billion in 2014 by marrying physical flows with financial flows in the supply chain [16]. There exist more than 30000 retailing stores for Haier Group in China ${ }^{4}$. Most of these retailing stores are franchisers, who are small firms and capital-constrained, and can not make a large order to Haier. To stimulate the retailing stores to make a larger order and boost the sales of product, Haier creates an innovative financing policy with rebate contract to them. Under this policy, Haier sets a Minimum Ordering Quantity (MOQ) to the retailing store according to its location and sales history. One distinguished difference from traditional rebate contract (e.g., [5,36], etc.), the new financing policy makes the retailer be able to raise capital from Haier's FSI (who cooperates with partner banks) but has to order a quantity that is not less than MOQ and be rebated the per unit excess that sells over the MOQ. Another distinguished difference is that the manufacturer would share a partial credit risk with the bank, and pays off the left principal and interest of loan if the retailer's selling revenue is less than her bankruptcy level with a MOQ threshold.

Similar to the case of Haier in China, many big companies' FSIs emerge as an important role in financing their customers. Therefore, in order to investigates the role and value of supply chain finance of FSIs, this paper builds up a new financing model (Model N) that incorporates rebate contract and considers a traditional bank financing service as the benchmark model (Model T).

Accordingly, some research questions are: (1) Under a given financing model (Model N and Model T), how the capital-constrained retailer and the supplier determine their ordering and wholesale price decisions, respectively? (2) How the model $\mathrm{N}$ affects the value of the supply chain with the capital-constrained retailer, and how the rebate contract impacts on equilibrium strategies between the retailer and the supplier under model N? (3) When two financing models are viable and competitive, whether there exists a Pareto zone in which all the players prefer model $\mathrm{N}$ rather than model $\mathrm{T}$ ?

To answer these questions, this study conducts a stylized newsvendor model in which the capital-constrained retailer can raise financing service by the model $\mathrm{T}$ or model $\mathrm{N}$, purchases product from the supplier, and then sells them in the retailing market with a random demand. To be easy traceable on analyzing the practice of FSI for the supplier, the FSI is considered as an external partner bank. The current study shows that when only financing model is viable, there exists an equilibrium strategy for the retailer and the supplier under each model, and the supplier could squeeze the retailer's profit to a very low even a zero level under model $\mathrm{N}$ since he bears the credit risk of retailer's financing and rebate commission, and tries to offset the potential loss from credit risk by charging a high wholesale price. In special, if the MOQ is so high that the retailer's order quantity is identical to MOQ, the supplier will monopolize the whole distribution channel and takes the integrated supply chain's profit. When two financing models are viable, this work shows that the optimal ordering quantity under model $\mathrm{N}$ is larger than that under model $\mathrm{T}$, and the prior could bring a higher supply chain profit when the

\footnotetext{
${ }^{1}$ The information is showed on http://finance.siemens.com/financialservices/global/en/pages/home.aspx, Oct 2 nd, 2015.

${ }^{2}$ The news is reported on http://nandu.media.baidu.com/article/3697501431826158962, Oct 2nd, 2015.

${ }^{3}$ The news is reported on http://www.e521.com/news/xyxw/422601.shtml, Oct 2nd, 2015.

${ }^{4}$ The news is reported on http://qd.sina.com.cn/news/finance/detailicesifvx6800850.shtml, Oct 2nd, 2015.
} 
MOQ level is not too high. And there exists a Pareto zone with a given rebate contract in which the model $\mathrm{N}$ outperforms the model T. Furthermore, some numerical experiments are performed to exemplify the theoretic results in this paper, and extend to examine how the supplier's rebate contract and marginal production cost impact on the Pareto zone.

In this proposed model, a rebate contract is incorporated into the traditional bank financing service, and the combined effect of MOQ level and rebate rate on equilibrium operational strategy is considered in capitalconstrained supply chain. Moreover, the strength of the new model over traditional bank financing model is examined. An adaptive rebate contract is provided for guiding the supplier to formulate a new financing policy. The rest of this paper is organized as follows. Section 2 reviews the relevant literature. Section 3 presents the framework of two finance models and gives some notations and the assumptions in this paper. Section 4 derives the equilibrium strategies of the supplier and the retailer under model $\mathrm{T}$ or model $\mathrm{N}$. Section 5 compares two models, analyzes the region of Pareto zone of model N. A set of numerical experiments is conducted in Section 6 to show the theoretical results in previous sections and even inspects how the rebate contract and the marginal production cost impact on the region of Pareto zone. Section 7 illustrates some managerial insights of current research. Section 8 concludes the paper and presents some future work. The proofs are included in the Appendix A.

\section{Literature REVIEW}

This paper belongs to the literature on the interaction with operation management and supply chain finance, and is closely related to two streams of research. The first related work is on supply chain finance and the other stream is related to sales rebate that the upstream supplier provides to the downstream retailer in the supply chain operational management. The two areas of studies are reviewed in this section.

\subsection{Supply chain finance}

In recent years, considerable attention has been focused on how to solve the financial problems of transactions between enterprises in supply chain. As for capital-constrained retailer, the supply chain finance channels are commonly divided into an internal financing channel that refers to trade credit based on EOQ model (e.g., $[9,25,31,35]$, etc.) between one buyer and one vendor in the supply chain, and an external financing channel that refers to the the financing service from a third party, in which, the bank financing based on newsvendor model is the most common strategy (e.g., $[14,39,41]$, etc.).

Buzacott and Zhang [4] investigated the financial and operational decisions with a budget-constrained retailer who borrows from a commercial bank, they presented the dynamical interaction between production and assets, and showed that the asset-based financing assists the retailer to improve the capital return. In their model, the bank operates in a non-competitive market, and seeks a maximum profit by deciding the loan interest and credit limit in the credit contract. Dada and $\mathrm{Hu}$ [14] employed a stackelberg game to solve the bank financing problem of a capital-constrained newsvendor, they examined the channel coordination mechanism that makes retailer's order quantity to be equal to the amount of unconstrained retailer. Xu and Birge [39] showed the optimal production decisions in the presence of newsvendor's financial constraints and managerial incentives. Gupta and Wang [19] built up a discrete time model of retailer's operations in the random demand circumstance, and examined the optimal base-stock inventory control policy with finance charges and payment rate. They found that the structure of retailer's optimal policy is not affected by credit terms.

Another stream of relative research is to investigate the value of supply chain finance by comparing the optimal strategies between the internal trade credit and bank financing model. For example, Zhou and Groenevelt [43] compared the trade and bank credit models for a limited-budget retailer in the supply chain, they assumed that the bank is monopolistic and profit-seeking and the retailer is allowed to purchase a part of the desired order due to credit line limit. The numerical analysis showed that bank credit is better than trade credit in some conditions. Babich et al. [3] examined the comparisons between bank and trade credit in different settings, and showed that the firm should choose finance channel with a lower finance cost. Caldentey and Chen [7] 
explored the value of delayed payment model (internal trade credit) in the supply chain, and showed that the manufacturer preferred an internal trade credit over bank financing when there exists competition between external and internal financing channels to the retailer. Kouvelis and Zhao [25] documented that a risk-neutral supplier always finance the retailer at less than or equal to the risk-free rate, and the retailer will always choose trade credit rather than bank financing in an optimally structured trade credit contract. Different to $[25,43]$, Jing et al. [23] examined the equilibrium financing channel with considering that the optimal interest rate for trade credit can be greater than the risk free rate, and the bank lends the loan to the retailer under a competitive market. In their model, the bank financing is more attractive for the retailer because the trade credit charges a higher wholesale price, and if the production cost is relatively low, the trade credit may be the unique equilibrium financing channel.

In addition, some literatures considered other respects in the bank financing model, for instance, Cai et al. [6] incorporated the firm's moral risk into the financing model, and analyzed the comparison between trade and bank credit for the supply chain. Cai et al. [22] showed that bank credit is less effective than trade credit in mitigating double marginalization with relatively low production cost. Chen [8] compared the bank and trade credit financing models under wholesale price contract and revenue-sharing contract, and found that trade credit betters off than bank financing for both participants in the supply chain. Several studies examined the impact of bankruptcy cost on the supply chain's operational decisions under the bank credit contract (e.g., $[2,26,42])$. Recently, some literatures investigated the financially weaker partner's bank financing model which incorporates a stronger partner's intermediary and guarantee, and analyzed the impact of risk sharing or warranty mechanism on the bank financing strategy (such as, [11,21,40]). Moussawai-Haidar et al. [30] considered a coordination mechanism for a three-level supply chain, which includes a capital-constrained supplier, a retailer and a bank. They developed the model that the supplier permits trade credit to the retailer and finances its capital with a discounted interest rate from the bank, and analyzed the coordination effect of minimizing the supply chain's cost. Alavi and Gaur [1] presented a stochastic robust optimization model to formulate the supply chain framework that could offer supply chain configuration decision and financing strategies when demand is uncertain. Kouvelis and Zhao [27] investigated the impact of supplier and retailers' credit ratings on the financial decisions of supply chain, they showed that if the supplier's credit rating is above some threshold, the supplier sets a zero interest rate in trade credit and the retailer will use trade credit only. Otherwise, the supplier offers a positive rate, which makes retailer to choose the combination of trade and bank credits.

\subsection{Sales rebate}

Our work is also related to the sales rebate contract in the supply chain. Most existing literatures examined the sales rebate from the standpoint of supply chain coordination. For example, Taylor [36] demonstrated the superiority of a target rebate in achieving a win-win situation and coordination in supply chain. Cachon and Lariviere [5] gave a comprehensive review on coordination contract, and compare the coordination effect of rebate and revenue-sharing contracts. Chen et al. [10] discussed the impact of manufacturer rebate on the performance of supply chain, and demonstrated that the rebate always benefits the manufacturer unless all the customers claim the rebate. Cho et al. [13] developed a model that both manufacturer and retailer can offer rebates to get additional sales, and presented a condition under which the firm will offer rebates. They found that if the manufacturer gives a more effective rebate program, both sides in supply chain will achieve win-win situation. Wong et al. [38] considered that a single supplier offers rebate contracts to multiple retailers in vendor-managed inventory partnership, and demonstrated that the supplier gains more profit with competing retailers than without competition between retailers. Chiu et al. [12] proposed a policy that combines the wholesale price, channel rebate, and returns to coordinate a channel with uncertain demand, and explored an equilibrium policy to achieve Pareto improvement for the members in supply chain. Gallego and Talebian [15] considered a setting, wherein tow providers compete for the broker, and investigated the effect of rebate contract on profit splitting between the providers and broker. They analyzed how the sales target in a rebate contract affects the revenue of the players in a competitive market. Ha et al. [20] considered the manufacturer rebate competition with two competing manufacturers selling to a retailer. They showed that with more intense competition between 
TABLE 1. Contributions of author(s).

\begin{tabular}{llllll}
\hline \hline Author(s) & $\begin{array}{l}\text { Determinate } \\
\text { demand }\end{array}$ & $\begin{array}{l}\text { Stochastic } \\
\text { demand }\end{array}$ & $\begin{array}{l}\text { Warranty } \\
\text { policy }\end{array}$ & $\begin{array}{l}\text { Rebate } \\
\text { contract }\end{array}$ & $\begin{array}{l}\text { Bank } \\
\text { financing }\end{array}$ \\
\hline Buzacott and Zhang [4] & NA & Yes & NA & NA & Yes \\
Cachon and Lariviere [5] & NA & Yes & NA & Yes & NA \\
Cho et al. $[13]$ & NA & Yes & NA & Yes & NA \\
Caldentey and Chen [7] & NA & Yes & NA & NA & Yes \\
Chiu et al. $[12]$ & NA & Yes & NA & Yes & NA \\
Kouvelis and Zhao $[25]$ & NA & Yes & NA & NA & Yes \\
Sarkar $[31]$ & Yes & NA & NA & NA & NA \\
Babich et al. $[3]$ & NA & Yes & NA & NA & Yes \\
Cai et al. $[6]$ & NA & Yes & NA & NA & Yes \\
Chen $[8]$ & NA & Yes & NA & NA & Yes \\
Sarkar and Saren $[32]$ & Yes & NA & Yes & NA & NA \\
Yan et al. $[40]$ & NA & Yes & Yes & NA & Yes \\
Alavi and Gaur $[1]$ & NA & Yes & NA & NA & Yes \\
Sarkar et al. $[33]$ & NA & Yes & NA & NA & NA \\
Guchhait t al. [18] $[18]$ & Yes & NA & Yes & NA & NA \\
Kumar et al. $[28]$ & Yes & NA & Yes & NA & NA \\
Sarkar et al. $[34]$ & Yes & NA & NA & NA & NA \\
Khanna et al. $[24]$ & Yes & NA & Yes & NA & NA \\
This paper & NA & Yes & Yes & Yes & Yes \\
\hline
\end{tabular}

Notes. "NA" stands for Not Applicable.

manufacturers, the rebate could benefits the manufacturers but hurts the retailer. Genc and Giovanni [17] analyzed the optimal rebate mechanism within a closed-loop supply chain. With consideration of consumer return behaviors, two types of rebates that include a fixed rebate and a variable rebate are investigated for the benefits of the whole supply chain. Their model showed that a variable rebate policy can lead to the supply chain's higher profit.

Table 1 shows a comparison of existing works and this paper. The contribution of current study lies in three aspects: First, to the best of our knowledge, this paper is the first to consider a rebate contract with financing warranty in supply chain finance. The proposed model $\mathrm{N}$ analyzes the impact of rebate contract on the financing strategy, and compares with the traditional model $\mathrm{T}$ to inspect the equilibrium condition of financing channel. The results show that given a production cost, the supplier can set an appropriate rebate contract to retailer's bank financing scheme, so that the model N is Pareto beneficial for each player in the supply chain. Second, different to the traditional sales rebate contract, this work not only discusses the supplier's rebates to the retailer, but also claims the retailer's order quantity that should not be less than the MOQ threshold. Hence, the rebate contract $(\alpha, \underline{q})$ is the revised rebate that compared to traditional sales rebate. Third, the warranty role of rebate contract is investigated in this paper. Different to some relevant literatures on the risk hedging means from the supplier or the third party, the current research discusses the supplier's guarantee on retailer's financing risk if the demand is lower than retailer's bankruptcy threshold with MOQ. The model N shows that if the supplier does not regulate the MOQ to guide the retailer's ordering, the supplier would not share any financing risk with the bank, then the supplier will raise the wholesale price with some rebate to retailer, under this circumstance, the retailer is not motivated to order more, and the model $\mathrm{N}$ is inferior to model $\mathrm{T}$ for the performance of supply chain. Therefore, the warranty role of the supplier's rebate contract plays an important part in the external bank financing channel for an underfunded supply chain. 


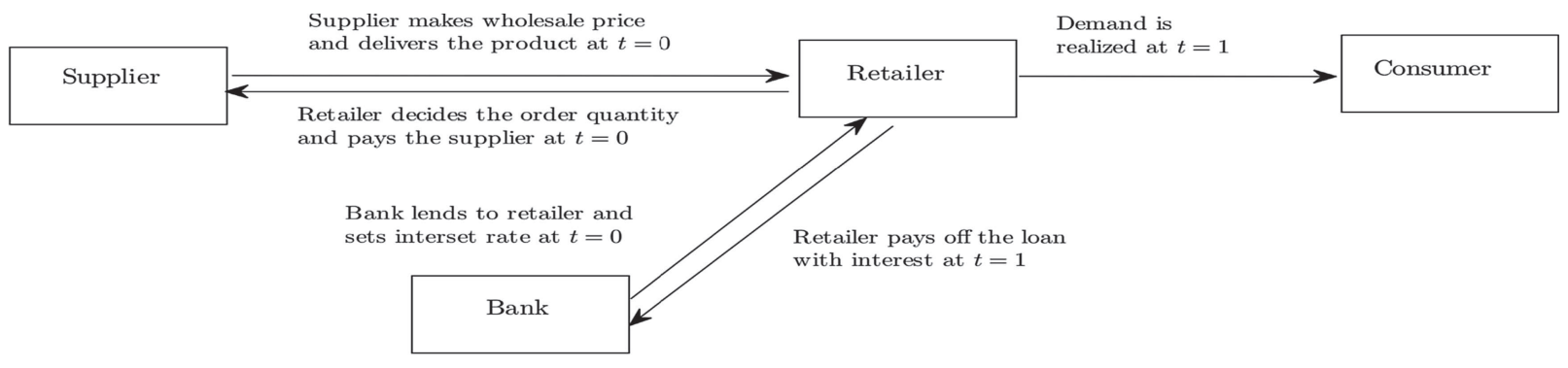

(a) The model $\mathrm{T}$

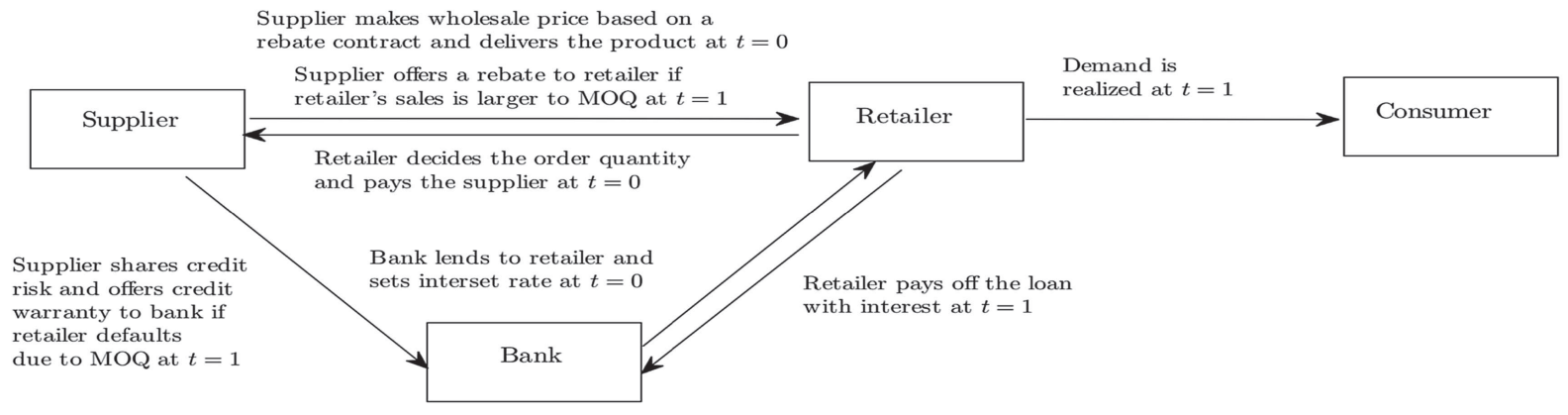

(b) The model $\mathrm{N}$

Figure 1. Comparison between two financing models. (a) The model T. (b) The model N.

\section{Problem Definition, notation, And ASSumptions}

\subsection{Problem definition}

This model is concerned with a two-echelon supply chain with a brand supplier (denoted by $S$, referred to herein as "he") and a capital-constrained retailer (denoted by $R$, referred to herein as "she") who buys a single type of product from the supplier and sells to a stochastic retailing market. Under the traditional financing model (Model T), the supplier sets a wholesale price. The capital-constrained retailer could borrow fund for procurement from the bank, she bears the credit risk by herself and naturally limits the loan amount.

Besides the borrowing capital by model $\mathrm{T}$, the retailer could raise capital from a FSI of the supplier. The role of the FSI is similar to the supplier's bank partner in the case of lending capital to his customers. For the convenience of study, the FSI of supplier can be considered as an external partner bank in this paper, who cooperates with the supplier and offers the capital-constrained retailer an innovative supply chain financing solution (Model N). Under model N, the supplier forces the retailer to purchase an ordering quantity that is not less than a Minimum Ordering Quantity (MOQ), rebates the retailer for every excess selling quantity over MOQ, and promises to share credit risk only when the market is so depressed that retailer's selling revenue is below the bankruptcy level of the MOQ. Figure 1 displays the comparison between two financing models. Under the two financing schemes, the supplier and retailer play a Stackelberg game, where the supplier is the leader and first makes the wholesale price, and retailer is the follower to decide the optimal order quantity. Different to model $\mathrm{T}$, the supplier sets the wholesale price according to a given rebate contract and shares a part of bank credit risk under model $\mathrm{N}$. 


\title{
3.2. Notations
}

\subsubsection{For the retailer}

The notations of decision variables and parameters for the capital-constrained retailer are as follows:

\section{Decision variables \\ Parameters \\ $p \quad$ retailer's retailing price for per unit (\$/unit) \\ $\pi_{r} \quad$ retailer's profit under model $\mathrm{T}(\$)$ \\ $\Pi_{r} \quad$ retailer's profit under model $\mathrm{N}(\$)$}

$q_{T} \quad$ retailer's order quantity under traditional financing model $\mathrm{T}$ (units)

$q_{N}$ retailer's order quantity under the new financing model $\mathrm{N}$ (units)

$q_{I} \quad$ retailer's optimal order quantity in an integrated supply chain (units)

\subsubsection{For the supplier}

The notations of decision variables and parameters for the supplier are as follows:

\author{
Decision variables \\ $w_{T} \quad$ supplier's wholesale price per unit under model T (\$/unit) \\ $w_{N} \quad$ supplier's wholesale price per unit under model $\mathrm{N}(\$ /$ unit $)$

\section{Parameters} \\ $q \quad$ minimum ordering quantity (MOQ) in supplier's rebate contract (units) \\ $\alpha \quad$ rebate rate for every excess selling quantity over MOQ (\$/unit) \\ $c \quad$ production cost per unit $(\$ /$ unit) \\ $\pi_{s} \quad$ supplier's profit under model $\mathrm{T}(\$)$ \\ $\Pi_{s} \quad$ supplier's profit under model $\mathrm{N}(\$)$
}

\subsubsection{Other notations}

$r_{T} \quad$ bank's financing rate under model $\mathrm{T}(\$ /($ time $\$))$

$r_{N} \quad$ bank's financing rate under model $\mathrm{N}(\$ /($ time $\$))$

$r_{f} \quad$ bank's risk-free interest rate $(\$ /($ time$\$)$

$\pi_{b} \quad$ bank's profit under model T $(\$)$

$\Pi_{b} \quad$ bank's profit under model $\mathrm{N}(\$)$

$\pi_{I} \quad$ supply chain's profit under model T $(\$)$

$\Pi_{I} \quad$ supply chain's profit under model $\mathrm{N}(\$)$

$D$ denotes a random market demand, which is a nonnegative variable and defined on $(0,+\infty)$

$f(\cdot) \quad$ the probability density function of $D$ and $f(\cdot)>0$

$F(\cdot) \quad$ the cumulative distribution function

$F^{-1}(\cdot)$ the inverse function of the distribution function

$\bar{F}(\cdot) \quad$ the complementary cumulative distribution function

$h(\cdot) \quad$ failure rate, $h(\cdot)=f(\cdot) / \bar{F}(\cdot)$

$H(\cdot) \quad$ generalized failure rate, $H(\cdot)=(\cdot) h(\cdot)$

$\mathbb{E}(\cdot) \quad$ mathematical expectation

$x^{+} \quad$ maximum value of $x$ and 0

\subsection{Assumptions}

(1) The bank has access to abundant funds and resides in a competitive financing market, that is, the expected profit of bank is zero. The risk-free interest rate $r_{f}$ is normalized to zero.

(2) The supplier has sufficient capital to produce and cover the retailer's ordering and the retailer has none initial budget for procurement. The bank credit is the sole channel to alleviate the dilemma of retailer's capital shortage, and the retailer has no other investment opportunity besides retail business. 
(3) The retailer has limited liability (e.g., [8,25,42], etc.), that is, if the retailer can not pay off the loan and interest, she declares bankruptcy and repays all the realized revenue and defaults the remaining portion of the bank credit obligation.

(4) The retailing price $p$ is normalized to be one. Each player's selling price should be larger than his/her cost for per unit, that is, $c \leq w_{T} \leq \frac{1}{1+r_{T}}$ and $c+\alpha \leq w_{N} \leq \frac{1}{1+r_{T}}$.

(5) Neither a salvage value nor a return policy for unsold units is considered in our model. Either party of supply chain is risk-neutral and the information asymmetry is neglected during the transaction between the supplier and retailer.

(6) The demand distribution has an increasing failure rate, that is, both $h(x)$ and $H(x)$ are increasing with $x$. This assumption is to ensure the existence of optimal solutions that is a common assumption in previous literature (e.g., $[23,25,29]$, etc.).

(7) The sales season is short and the time is assumed to be one unit, such as one quarter, one month, one week, etc.

\section{EQUILIBRIUM ANALYSIS}

This section inspects the equilibrium strategies between the supplier and the retailer when only one financing model (Model T or Model N) is viable, and analyze how the financing model influences the decisions of both the supplier and the retailer.

\subsection{Traditional bank financing service (Model T)}

Under model $\mathrm{T}$, the supplier will neither require retailer to make a minimum ordering, nor share any bank credit risk if retailer is bankruptcy. Thus, the model $\mathrm{T}$ is similar to the classic newsvendor model. As Figure 1a shows, the sequence of events is as follows.

At the beginning of sales season (time $t=0$ ), the supplier makes the wholesale price $w_{T}$ and then retailer decides her order quantity $q_{T}$. Due to the shortage of procurement capital, the retailer borrows from the bank and the bank sets the financing rate $r_{T}$ from the balance between payment and expected revenue. At the same time, after receiving the payment of product, the supplier delivers the product to retailer. At the end of sales season (time $t=1$ ), the demand is realized and retailer settles accounts and repays the bank of her loan and interest. If retailer is insolvent, the bank bears the credit risk. As a result, the retailer's ordering decision is derived from following equation:

$$
\begin{array}{cc}
\max _{q_{T} \geq 0} & \pi_{r}=\mathbb{E}\left[\min \left(D, q_{T}\right)-w_{T} q_{T}\left(1+r_{T}\right)\right]^{+} \\
\text {Subject to (s.t.) } & \mathbb{E} \min \left[\min \left(D, q_{T}\right), w_{T} q_{T}\left(1+r_{T}\right)\right]=w_{T} q_{T},
\end{array}
$$

and the supplier's problem is

$$
\max _{w_{T} \in\left[c, \frac{1}{1+r_{T}}\right]} \pi_{s}=\left(w_{T}-c\right) q_{T}
$$

The left side of equation (4.2) is the bank's expected gainings from the retailer, and the right side is retailer's loan that bank offers. Under the perfect competitive market, the bank's expected profit is zero, which implies that the cost of bank credit is identical to that retailer takes her own capital given that she has enough fund. With backward induction, we can solve each participant's decision problem and give the equilibrium strategy as following.

Lemma 4.1. Under model $T$, (1) the capital-constrained retailer's optimal order quantity $q_{T}^{*}$ is uniquely given by $\bar{F}\left(q_{T}^{*}\right)\left(1-H\left(q_{T}^{*}\right)\right)=c$; (2) the supplier's wholesale price is $w_{T}^{*}=\bar{F}\left(q_{T}^{*}\right) ;(3)$ bank's interest rate $r_{T}^{*}$ is the unique solution of $w_{T}^{*} q_{T}^{*} r_{T}^{*}=\int_{0}^{w_{T}^{*} q_{T}^{*}\left(1+r_{T}^{*}\right)} F(x) \mathrm{d} x$. 
Lemma 4.1 reflects that the retailer's ordering and supplier's pricing decisions are identical to those results under the newsvendor model with no budget constraint. Just as [7], because a competitive financial market leads to a zero profit of bank and allows the supply chain to operate in the same way that the retailer has no capital constraints, so the retailer makes an order quantity just as under the classic newsvendor model. Under this case, the optimal expected profits of retailer and supplier are

$$
\begin{aligned}
& \pi_{r}=q_{T}^{*} F\left(q_{T}^{*}\right)-\int_{0}^{q_{T}^{*}} F(x) \mathrm{d} x . \\
& \pi_{s}=\left(\bar{F}\left(q_{T}^{*}\right)-c\right) q_{T}^{*} .
\end{aligned}
$$

\subsection{New bank financing with rebate contract (Model $N$ )}

Different to model $\mathrm{T}$, model $\mathrm{N}$ offers a mechanism in which the supplier encourages not only the retailer to sell product but also the partner bank to lend capital to the retailer by sharing part of credit risk.

Under model $\mathrm{N}$, the retailer makes an order quantity $q_{N}$ that is not less than $q$, and she borrows a loan of $w_{N} q_{N}$ from bank, and the principle and interest of loan should be $w_{N} q_{N}\left(1+r_{N}\right)$, which is the bankruptcy threshold of retailer. If the retailer's revenue is lower than $w_{N} q_{N}\left(1+r_{N}\right)$, then retailer is bankrupt and default. Obviously, the retailer's bankruptcy threshold level $w_{N} q_{N}\left(1+r_{N}\right) \geq w_{N} \underline{q}\left(1+r_{N}\right)$. Only when market demand $D$ is lower than $w_{N} \underline{q}\left(1+r_{N}\right)$, the supplier will compensate the bank with financing guarantee fund $w_{N} \underline{q}\left(1+r_{N}\right)-D$. Otherwise, the supplier will not provide any warranty for the financing risk between retailer and bank. Thus, the supplier stipulates a MOQ $\underline{q}$ for retailer and will be responsible for this part of credit risk $w_{N} \underline{q}\left(1+r_{N}\right)$. On the other hand, in order to motivate the retailer to promote the sales, the supplier rebates the retailer with an $\alpha$ for each excess sales over MOQ. So, the retailer will obtain additional rewarding $\alpha\left[\min \left(D, q_{N}\right)-\underline{q}\right]^{+}$. The framework of model $\mathrm{N}$ can be illustrated by Figure 1b, and the sequence of events is as following.

At time $t=0$, the supplier signs a rebate contract $(\alpha, q)$ with retailer, and then sets the wholesale price $w_{N}$ that is correlated to that rebate contract. Then, after observing the procurement information, the retailer makes her order quantity $q_{N}$ and borrows the loan of $w_{N} q_{N}$ from the bank. Meanwhile, the bank calculates the financing rate $r_{N}$ under the competitive finance market, and offers the loan to the retailer. After receiving the retailer's payment, the supplier distributes the product. At time $t=1$, the demand is realized and each participant checks the profit as: the retailer gains the incoming from the sales market and reward of excess sales over $\underline{q}\left(\right.$ i.e., $\left.\alpha\left[\min \left(D, q_{N}\right)-q\right]^{+}\right)$, and repays the bank of her loan and interest. If the retailer's total property could not pay back her debts, the retailer declares bankrupt and pays the whole equity to bank. The supplier pays the sales award to retailer and offers a compensation of $\left[w_{N} q\left(1+r_{N}\right)-D\right]^{+}$to bank. The bank collects the repayments from retailer and supplier, and make a loss if the repayments are less than $w_{N} q_{N}\left(1+r_{N}\right)$. Therefore, the retailer's problem can be written as:

$$
\begin{aligned}
\max _{q_{N} \geq \underline{q}} & \Pi_{r}=\mathbb{E}\left[\min \left(D, q_{N}\right)+\alpha\left(\min \left(D, q_{N}\right)-\underline{q}\right)^{+}-w_{N} q_{N}\left(1+r_{N}\right)\right]^{+} \\
\text {s.t. } & \mathbb{E} \min \left[\min \left(D, q_{N}\right)+\alpha\left(\min \left(D, q_{N}\right)-\underline{q}\right)^{+}+\left(w_{N} \underline{q}\left(1+r_{N}\right)-D\right)^{+}, w_{N} q_{N}\left(1+r_{N}\right)\right]=w_{N} q_{N} .
\end{aligned}
$$

Note that, if $w_{N} q_{N}\left(1+r_{N}\right) \geq D$, then supplier will not share the credit risk, in this case, when $D \geq \underline{q}$ and $D+\alpha(D-\underline{q}) \leq w_{N} q_{N}\left(1+r_{N}\right)\left(i . e ., \underline{q} \leq D \leq \frac{w_{N} q_{N}\left(1+r_{N}\right)+\alpha \underline{q}}{1+\alpha}\right)$, the retailer's incoming is less than her loan and interest $w_{N} q_{N}\left(1+r_{N}\right)$, which makes her go bankruptcy and defaults. So, let $\theta=\frac{w_{N} q_{N}\left(1+r_{N}\right)+\alpha \underline{\underline{q}}}{1+\alpha}$, the bank's problem in equation (4.7) can be reduced as follows:

$$
w_{N} q_{N} r_{N}= \begin{cases}(1+\alpha) \int_{\underline{q}}^{\theta} F(x) \mathrm{d} x+\int_{w_{N}\left(1+r_{N}\right) \underline{q}}^{\underline{q}} F(x) \mathrm{d} x, & \underline{q} \leq w_{N} q_{N}\left(1+r_{N}\right), \\ \int_{w_{N}\left(1+r_{N}\right) \underline{q}}^{w_{N}\left(1+r_{N}\right.} F(x) \mathrm{d} x, & q_{N} \geq \underline{q}>w_{N} q_{N}\left(1+r_{N}\right),\end{cases}
$$


and the supplier's problem is

$$
\max _{c+\alpha \leq w_{N} \leq \frac{1}{1+r_{N}}} \Pi_{s}=\mathbb{E}\left[\left(w_{N}-c\right) q_{N}-\alpha\left(\min \left(D, q_{N}\right)-\underline{q}\right)^{+}-\left(w_{N} \underline{q}\left(1+r_{N}\right)-D\right)^{+}\right] .
$$

To solve each participant's decision problem, we first examine the existence of optimal solution to bank's interest rate and supplier's wholesale price.

Lemma 4.2. Given a rebate contract $(\alpha, \underline{q})$, (1) If $\Pi_{r} \geq 0$, the bank credit is feasible and there exists a positive $r_{N}$ for bank's decision problem; (2) supplier's profit $\Pi_{s}$ is a concave function of $w_{N}$.

Lemma 4.2 shows that for a given rebate contract, the bank can set a feasible interest rate for financing the retailer, and the supplier can find an optimal wholesale price, which satisfies the first order condition of equation (4.9). Applying the backward induction method, Proposition 4.3 summarizes the optimal decisions under model $\mathrm{N}$.

Let $\widehat{q_{N}}$ is uniquely solved by $\bar{F}\left(q_{N}\right)\left[1-(1+\alpha) H\left(q_{N}\right)+(1+\alpha)\left(1+r_{N}^{*}\right) h\left(q_{N}\right) \underline{q} F\left(w_{N}^{*}\left(1+r_{N}^{*}\right) \underline{q}\right)\right]=c$, Proposition 4.3 characterizes each player's equilibrium strategy.

Proposition 4.3. Under model $N$ with a rebate contract $(\alpha, q)$, (1) If $\widehat{q_{R}}>q$, the optimal operational decisions are $\left(q_{N}^{*}, w_{N}^{*}\right)=\left(\widehat{q_{N}},(1+\alpha) \bar{F}\left(\widehat{q_{N}}\right)\right)$ and the bank sets the interest rate $r_{N}^{*}$ which is the unique positive root of equation (4.8). (2) If $\widehat{q_{N}} \leq \underline{q}$, the optimal decision is $\left(q_{N}^{*}, w_{N}^{*}, r_{N}^{*}\right)=(\underline{q}, 1,0)$.

Proposition 4.3 shows that under model N, each participant's operational strategy is dependent on supplier's rebate contract. If the MOQ $q$ is larger to some extent, the retailer is compelled to make the order amount that equals $q$ even when demand is small, then supplier will fix a highest price that equals to retail price, and bank's financing interest rate is zero. The intuitive explanation is that supplier enhances the buyer's ordering threshold and deprives all the retailer's profit, which is identical to that supplier performs a direct-sales plan and sells the product to consumer by himself. Thanks to his abundant fund, the supply chain has no capital constraints and the bank will not offer the financing service. Therefore, improving the MOQ level may lead to retailer's loss. Proposition 4.3 also shows that the rebate contract impacts the retailer's order plan and supplier's pricing strategy. The following Corollary 4.4 characterizes the impact of two exogenous variables $\alpha$ and $\underline{q}$ on $\left(q_{N}^{*}, w_{N}^{*}\right)$.

Corollary 4.4. (1) $\frac{\partial q_{N}^{*}}{\partial \alpha} \leq 0, \frac{\partial q_{N}^{*}}{\partial q} \geq 0$; (2) $\frac{\partial w_{N}^{*}}{\partial \alpha} \geq 0, \frac{\partial w_{N}^{*}}{\partial q} \leq 0$.

Corollary 4.4 shows that retailer's order quantity and supplier's wholesale price have an opposite effect with $\alpha($ or $q$ ). Given a MOQ $q$, the retailer's order quantity is decreasing with rebate rate $\alpha$, while supplier's optimal price increases with $\alpha$. And fixed a rebate rate $\alpha$, retailer's order quantity increases with $q$, while the wholesale price decreases with $q$.

Under model $\mathrm{N}$, the profits of retailer and supplier can be further simplified as follows:

$$
\begin{aligned}
& \Pi_{r}=\left(1-w_{N}^{*}\right) q_{N}^{*}-\int_{w_{N}^{*}\left(1+r_{N}^{*}\right) \underline{q}}^{q_{N}^{*}} F(x) \mathrm{d} x+\alpha\left[\left(q_{N}^{*}-\underline{q}\right)-\int_{\underline{q}}^{q_{N}^{*}} F(x) \mathrm{d} x\right] . \\
& \Pi_{s}=\left(w_{N}^{*}-c\right) q_{N}^{*}-\int_{0}^{w_{N}^{*}\left(1+r_{N}^{*}\right) \underline{q}} F(x) \mathrm{d} x-\alpha\left[\left(q_{N}^{*}-\underline{q}\right)-\int_{\underline{q}}^{q_{N}^{*}} F(x) \mathrm{d} x\right] .
\end{aligned}
$$

Intuitively, under model $\mathrm{N}$, the supplier offers a rebate contract to incentive the retailer to make a larger selling, and shares a partial credit risk with the bank if the demand is small. As a leader in the game, the supplier should naturally set a higher wholesale price to offset his payment of rebates for the retailer and financing guarantee for the bank. Nevertheless, a higher wholesale price $\left(e . g ., w_{N}=1\right)$ could lead to a zero profit for the retailer, thus the retailer should refuse to accept model $\mathrm{N}$, and could choose model $\mathrm{T}$ instead if traditional financing channel is also viable. Therefore, next section further examines the value of model $\mathrm{N}$ for both retailer, supplier and the whole supply chain. 


\section{The VAlue of NeW FinANCING POLICY}

As mentioned before, without considering the competition between two financing models, under model N, the supplier could set a high MOQ in rebate contract and draws all of supply chain profit. However, when two financing models are viable, the players have to consider the competition between two financing models, and choose the right financing model to maximize their profits. To study the role and the value of new financing policy in the supply chain, this section compares model $\mathrm{N}$ with model $\mathrm{T}$, inspects how each participant chooses the right financing model, and shows there exists a Pareto Zone in which model $\mathrm{N}$ outperforms model $\mathrm{T}$ for each party in supply chain.

\subsection{Comparisons of participant's equilibrium strategy}

This subsection compares the retailer's ordering and supplier's pricing strategies under models $\mathrm{T}$ and $\mathrm{N}$ as follows.

Let $\underline{\tilde{q}}=\frac{\bar{F}^{-1}\left(\frac{1}{1+\alpha}\right)}{1+r_{N}^{*}}>0$ and $\tilde{\alpha}=\frac{1}{1-\left(1+r_{N}^{*}\right) F\left(w_{N}^{*}\left(1+r_{N}^{*}\right) \underline{q}\right)}-1>0$, the comparison between retailer's ordering strategies is concluded in Lemma 5.1.

Lemma 5.1. (1) Given an $\alpha \geq 0$ in rebate contract, if $\alpha=0$, then $q_{N}^{*} \geq q_{T}^{*}$; If $\alpha>0$, then $q_{N}^{*}<q_{T}^{*}$ with $\underline{q}<\underline{\tilde{q}}$ and $q_{N}^{*} \geq q_{T}^{*}$ with $\underline{q} \geq \underline{\tilde{q}}$. (2) Given a $\underline{q} \geq 0$ in rebate contract, if $\underline{q}=0$, then $q_{N}^{*} \leq q_{T}^{*}$; If $q_{N}^{*}>\underline{q}>0$, then $q_{N}^{*} \geq q_{T}^{*}$ with $0 \leq \alpha \leq \tilde{\alpha}$ and $q_{N}^{*}<q_{T}^{*}$ with $\alpha>\tilde{\alpha}$; If $q_{N}^{*}=\underline{q}>0$, then $q_{N}^{*} \geq q_{T}^{*}$.

Lemma 5.1 suggests that retailer's order quantity under model $\mathrm{N}$ depends on a given rebate contract. If the supplier does not provide rebate reward for retailer's excess sales $(\alpha=0)$, then a positive MOQ level motivates the retailer to make a larger quantity under model $\mathrm{N}$ than that under model $\mathrm{T}$. While the supplier sets a positive rebate rate in contract, only with the MOQ that is larger to some threshold $\tilde{q}$, the retailer will be initiated to order more product. As far as the MOQ level is concerned, if MOQ is low $(\underline{q}=0)$, then the retailer makes a lower ordering than model T although the supplier offers rebates to retailer. If MOQ is medium $\left(q_{N}^{*}>\underline{q}>0\right)$, as long as supplier's rebate rate is not large to some extent $(\alpha \leq \tilde{\alpha})$, the retailer's order amount is larger than that under model T. In special, if MOQ is so high that compels the retailer to make ordering which equals $\underline{q}$, the supplier could set sales amount from the view of the integrated supply chain, and $\underline{q}$ will be larger than $\bar{q}_{T}^{*}$ $\left(e . g ., \underline{q}=q_{I}>q_{T}^{*}\right)$. Therefore, under the traditional bank financing service, the supplier can use rebate contract to enhance retailer's order quantity. If the retailer wants to get a higher rebate rate from supplier, she should face a greater sales pressure and undertakes a larger MOQ amount.

Next, Lemma 5.2 concludes a comparison of supplier's optimal wholesale price between two financing models as follows.

Lemma 5.2. Under model $N$, if $\alpha=0$, then $w_{N}^{*} \leq w_{T}^{*}$; If $\alpha \geq \tilde{\alpha}>0$, then $w_{N}^{*} \geq w_{T}^{*}$.

Lemma 5.2 implies that in the case that the supplier requires retailer's ordering to be not less than MOQ but provides none rebate rewards to retailer, the wholesale price should be lower under model $\mathrm{N}$ than that under model $\mathrm{T}$, so that the retailer will be encouraged to make a larger order quantity. If the supplier pays some rewards to encourage retailer's sales, then he should make a higher price to the retailer to offset this part of payment. Lemma 5.1 shows that if $\alpha \geq \tilde{\alpha}$, whatever the MOQ is, the supplier's pricing strategy leads to retailer's lower ordering under model $\mathrm{T}$.

\subsection{Comparisons of participant's profit}

This subsection analyzes each player's financing choice between two models by comparing the profits of capital-constrained retailer and supplier respectively. 


\subsubsection{Comparison of retailer's profit}

From the above Lemmas 5.1 and 5.2, retailer's optimal quantity and supplier's wholesale price are dependent on the given rebate contract $(\alpha, q)$. The value of new financing strategy on retailer could be further analyzed by comparing retailer's profit that is demonstrated in equation (4.4) under model $\mathrm{T}$ and equation (4.10) under model N. For ease of explanation, fix the MOQ $\underline{q}$ as an exogenous variable and analyze the impact of $\alpha$ on retailer's profit. Let $X(\alpha, \underline{q})=\alpha\left[q_{N}^{*} F\left(q_{N}^{*}\right)-\underline{q}-\int_{\underline{q}}^{q_{N}^{*}} F(x) \mathrm{d} x\right]+\int_{0}^{w_{N}^{*}\left(1+r_{N}^{*}\right) \underline{q}} F(x) \mathrm{d} x$, the following proposition concludes the comparison of retailer's profit.

Proposition 5.3. (1) If $q_{N}^{*}>q>0$, then $\Pi_{r} \geq \pi_{r}$ with condition that $\alpha<\tilde{\alpha}$ and $X(\alpha, q) \geq 0$, and $\Pi_{r}<\pi_{r}$ with condition that $\alpha \geq \tilde{\alpha}$ and $\bar{X}(\alpha, \underline{q})<0$. (2) If $q_{N}^{*}=\underline{q}$, then $\Pi_{r}<\pi_{r}$.

The fist part of Proposition 5.3 shows that when the supplier gives a low or median MOQ threshold and a small rebate rate $\alpha$, the model $\mathrm{N}$ will betters off than model $\mathrm{T}$ for retailer. Note that, contrary to common sense, if the rebate rate $\alpha$ is lower to some extent (i.e., combined with Corollary $4.4, X(\alpha, q) \geq 0$ implies $\alpha$ is lower than some level), the retailer will be more favorable under new financing strategy. The cause is that the wholesale price is increasing with respect to $\alpha$, which directly impairs the retailer's order quantity and profit. However, if the supplier raises MOQ to be a high level, which leads to the retailer facing a strict order requirement $\left(q_{N}^{*}=q\right)$, then retailer's profit is zero under model $\mathrm{N}$, and she will abandon the rebate contract and prefers model $\mathrm{T}$ to finance her procurement.

Corollary 5.4. (1) If $\alpha=0$, then $\Pi_{r}>\pi_{r}$. (2) If $\underline{q}=0$, then $\Pi_{r}>\pi_{r}$ if and only if $\alpha>\frac{q_{T}^{*} F\left(q_{T}^{*}\right)-\int_{0}^{q_{T}^{*}} F(x) \mathrm{d} x}{q_{N}^{*} F\left(q_{N}^{*}\right)-\int_{0}^{q_{N}^{*}} F(x) \mathrm{d} x}-1$.

Corollary 5.4 demonstrates the comparison of retailer's profit with two special cases in model N. If the supplier does not offer rebate rewards to retailer, Lemma 5.2 shows that the supplier makes a lower wholesale price, which results in retailer's larger order quantity under new financing scheme, then retailer's profit is larger than that under model $\mathrm{T}$. While if the supplier does not give any minimum threshold for retailer's ordering, Lemma 5.1 shows that the retailer will order less than that under traditional financing channel, then the retailer prefers model $\mathrm{N}$ only with a high rebate rate. Therefore, Corollary 5.4 further suggests that compared to rebate rate $\alpha$, the MOQ in rebate contract impacts retailer's ordering more significantly and plays a more important role in retailer's choice of financing schemes.

\subsubsection{Comparison of supplier's profit}

Similar to the comparison of retailer's profit, the supplier's profits under two models are compared with the assumption that MOQ is given as a constant and the effect of $\alpha$ in rebate contract is examined. The payoff of supplier is given in equations (4.5) and (4.11) under model $\mathrm{T}$ and model $\mathrm{N}$ separately. Let $\check{\alpha}=$ $-\frac{\left(\bar{F}\left(q_{T}^{*}\right)-c\right) q_{T}^{*}-\left(\bar{F}\left(q_{N}^{*}\right)-c\right) q_{N}^{*}+\int_{0}^{w_{N}^{*}\left(1+r_{N}^{*}\right) \underline{q}}}{q_{N}^{*} F\left(q_{N}^{*}\right)-\underline{q}-\int_{\underline{N}}^{q_{N}^{*}} F(x) \mathrm{d} x}$, the results are summarized in the next Proposition 5.5.

Proposition 5.5. (1) Given a MOQ level $\underline{q}$ such that $q_{N}^{*}>\underline{q}>0$, if $X(\alpha, \underline{q}) \geq 0$, then $\Pi_{s} \leq \pi_{s}$; If $X(\alpha, \underline{q})<0$, then $\Pi_{s} \geq \pi_{s}$ if and only if $\alpha \geq \check{\alpha}$. (2) If $q_{N}^{*}=q$, then $\Pi_{s}>\pi_{s}$.

Proposition 5.5 reveals that, if the supplier gives a low and medium MOQ, then model $\mathrm{N}$ with a higher rebate rate outperforms model $\mathrm{T}$ for the supplier. So, the impact of $\alpha$ on the supplier shows an opposite impact of $\alpha$ on retailer (see Prop. 5.3). Because under new financing scheme, a higher rebate rate leads to a higher wholesale price (see Lem. 5.2), and the supplier enhances the selling price to offset the payment of retailer's rebate rewards and the warranty fund for the bank credit financing risk. Thus, the supplier would like to set a high rebate rate for his own benefit in the rebate contract under model N. In addition, a much high MOQ level results in supplier's maximum profit, because in this case, the supplier will get the payoff of the integrated supply chain. 
Corollary 5.6. If $\alpha=0$ or $q=0$, then $\Pi_{s} \leq \pi_{s}$.

Corollary 5.6 shows that either the rebate rate or MOQ threshold to be zero is not beneficial for the supplier under model N. That is to say, in order to get more payoffs than the gainings under model T, the supplier should formulate a rebate contract in retailer's financing scheme which includes a positive MOQ level and a positive rebate rate $\alpha$. Besides traditional financing policy for the capital-constrained retailer, the supplier will improve his own profit by offering some rewards to retailer's sales and meanwhile requiring some minimum order quantity.

\subsection{The Pareto zone of new financing policy}

In the above subsection, model $\mathrm{N}$ shows an inconsistent impact on retailer's profit and supplier's profit, so whether there exists an effective zone that model $\mathrm{N}$ is Pareto beneficial for both the retailer and the supplier in the supply chain? To answer this question, this subsection first examines how model $\mathrm{N}$ affects the performance of the entire supply chain, and then discusses the benefit of each player. Thanks to that bank earns zero in the competitive finance market, the whole supply chain's profit under two models are written as follows.

$$
\begin{gathered}
\pi_{I}=\pi_{r}+\pi_{s}=(1-c) q_{T}^{*}-\int_{0}^{q_{T}^{*}} F(x) \mathrm{d} x . \\
\Pi_{I}=\Pi_{r}+\Pi_{s}=(1-c) q_{N}^{*}-\int_{0}^{q_{N}^{*}} F(x) \mathrm{d} x .
\end{gathered}
$$

Proposition 5.7. Given a $\underline{q}>0$, if $\alpha \leq \tilde{\alpha}$, then $\Pi_{I} \geq \pi_{I}$.

Proposition 5.7 indicates that model $\mathrm{N}$ can create new value to the entire supply chain if the optimal quantity under new financing policy is larger than that under model T. Combined Lemma 5.1, a suitable rebate contract that is provided from supplier can initiate retailer to make a larger ordering and then improves the profit of whole supply chain. Suppose that the MOQ $\underline{q}$ is given so high that the retailer makes an order equaling to $\underline{q}$, then the supplier should set $\underline{q}=q_{I} \geq q_{T}^{*}$ and gets an optimal profit of the integrated supply chain. Subsequently, the MOQ is very important to the performance of supply chain with a capital-constrained retailer.

Next, whether model $\mathrm{N}$ benefits the individual player in the supply chain besides of the entire supply chain is investigated. Let $\bar{\alpha}=\min \left(\tilde{\alpha}, \frac{q_{N}^{*} F\left(q_{N}^{*}\right)-q_{T}^{*} F\left(q_{T}^{*}\right)-\int_{q_{T}^{*}}^{q_{N}^{*}} F(x) \mathrm{d} x+\int_{0}^{w_{N}^{*}\left(1+r_{N}^{*}\right) \underline{q}} F(x) \mathrm{d} x}{\underline{q}_{-} q_{N}^{*} F\left(q_{N}^{*}\right)+\int_{\underline{q}}^{q_{N}^{*}} F(x) \mathrm{d} x}\right), U(\alpha)=\underline{q}-q_{N}^{*} F\left(q_{N}^{*}\right)+$ $\int_{\underline{q}}^{q_{N}^{*}} F(x) \mathrm{d} x$ and $\underline{\alpha}=\check{\alpha}$, the following proposition concludes the results.

Proposition 5.8. Given a $\underline{q}$ such that $\left.q_{N}^{*}>q\right) 0$, if $\underline{\alpha}<\bar{\alpha}$ and $U(\alpha)>0$, then there exists a Pareto zone of $[\underline{\alpha}, \bar{\alpha}]$, in which model $N$ outperforms model $T$ for all the players.

Since all the players prefer to choose model $\mathrm{N}$ rather than model $\mathrm{T}$ within the above Pareto zone, the supplier should have the incentive to offer model $\mathrm{N}$ to the retailer and creates new value to individual and the entire supply chain. However, the existence of Parezo zone depends on the condition with $\underline{\alpha}<\bar{\alpha}$, which is impacted by MOQ $q$ and the supplier's production cost $c$. The next section examines how $\underline{q}$ and $c$ affect the evolution of Pareto zone.

\section{NUMERICAL EXAMPLES AND SENSITIVITY ANALYSIS}

This section presents some numerical examples to verify and extends the analysis in previous sections, and illustrates the impacts of rebate contract on supplier's pricing strategy and retailer's order decision, as well as the payoffs for each participant under different financing models. In addition, the sensitivity analysis is performed to illustrate the combined effect of production cost and rebate contract on the evolution of Pareto zone of equilibrium financing models, which benefits both parties in financing contract. 


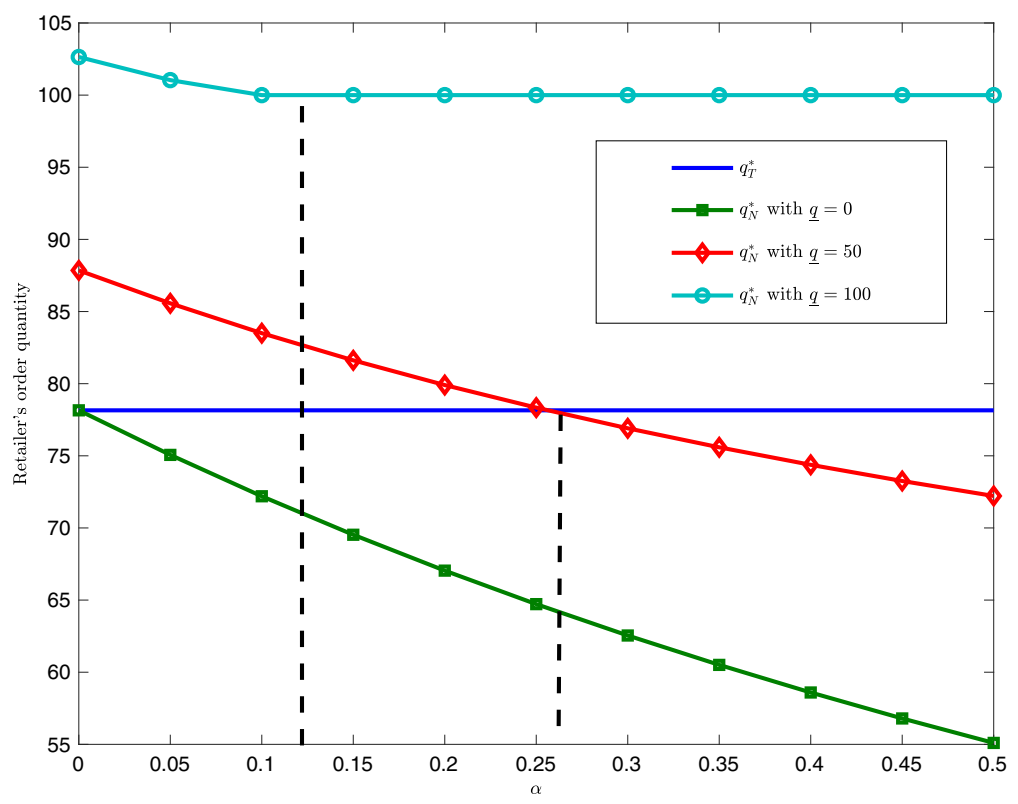

FIGURE 2. The impact of $\alpha$ on the retailer's optimal order quantity.

\subsection{Numerical examples}

Example 1: set the market demand follows an exponential distribution with mean value of 100 units, the cumulative function is $F(x)=1-\exp (-x / 100)$, the product cost per unit $c=\$ 0.1 /$ units. Under model T, the players' optimal decisions are $q_{T}^{*}=78.15$ units, $w_{T}^{*}=\$ 0.4577 /$ unit and each party's profit is $\pi_{r}=\$ 18.4581$ and $\pi_{s}=\$ 27.9557$, the integrated supply chain's profit is $\pi_{I}=\$ 46.4139$. Assume the MOQ threshold $q=$ 0 (or 50,100 ) units under model $\mathrm{N}$, the impacts of rebate $\alpha$ on retailer's optimal order quantity and supplier's wholesale price are plotted as Figures 2 and 3, and the impacts of $\alpha$ on retailer's profit and supplier's profit are separately plotted as Figures 4 and 5 .

Figure 2 shows that under model N, retailer's optimal order quantity is decreasing with the rebate rate $\alpha$ in a given rebate contract, which is consistent with Corollary 4.4. Relative to the optimal order quantity under model $\mathrm{T}$, the retailer will make a lower ordering if the supplier does not set any MOQ under new financing policy. While given a median MOQ (e.g., $q=50)$, a small rebate rate $\alpha(e . g ., \alpha \leq 0.25)$ will improve retailer's order quantity, otherwise, retailer's order quantity will decrease. If the MOQ is high to some level (e.g., $q=100)$, then the retailer's order is larger than the MOQ level with a small rebate rate $\alpha$ (e.g., $\alpha \leq 0.1)$. With increasing the rebate rate, the supplier rises the wholesale price, and then the retailer is not motivated to order more than MOQ, in this case, the retailer faces much sales pressure from supplier's regulation.

Figure 3 illustrates that the supplier's wholesale price increases with rebate rate $\alpha$, when $q=0$, the wholesale price under model $\mathrm{N}$ is larger than that under model $\mathrm{T}$. If the MOQ is median (e.g., $q=5 \overline{0})$, the supplier will set a higher price with $\alpha \geq 0.07$. And if the MOQ is high (e.g., $q=100)$, the supplier sells to retailer at the highest price, this result verifies Proposition 4.3.

Figure 4 plots the impact of rebate rate on retailer's profit. As a whole, the retailer's profit is deceasing with $\alpha$. Given $q=0$, that is, the supplier does not exert any pressure on retailer's ordering, a higher rebate rate leads to a lower profit of the retailer under model $\mathrm{N}$, which is contrary to the common sense that a higher rebate rate initiates retailer to make a larger order and get more profit. Because the supplier offers a high rebate rewards to retailer and meanwhile sets a high wholesale price, which constraints retailer's order quantity, thus, the retailer's profit is lower than that under model T. While, if $\underline{q}=50$ units (or 100), the model $\mathrm{N}$ benefits the 


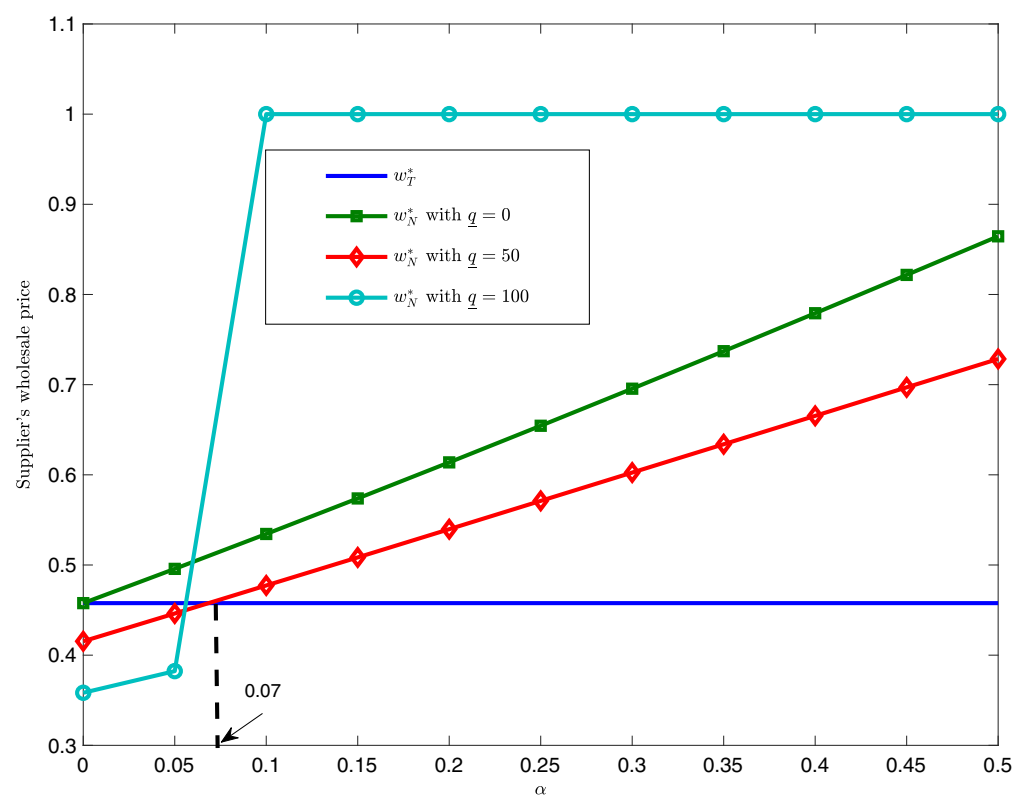

Figure 3. The impact of $\alpha$ on the supplier's wholesale price.

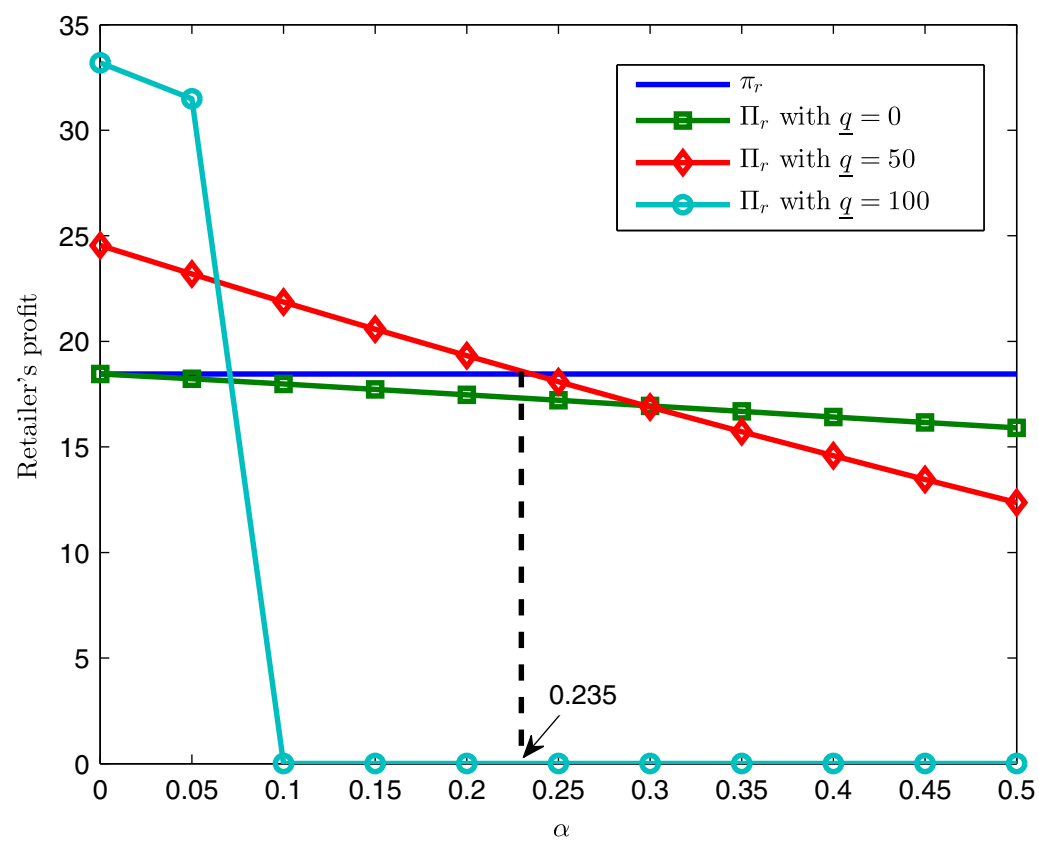

FIgURE 4 . The impact of $\alpha$ on the retailer's profit. 


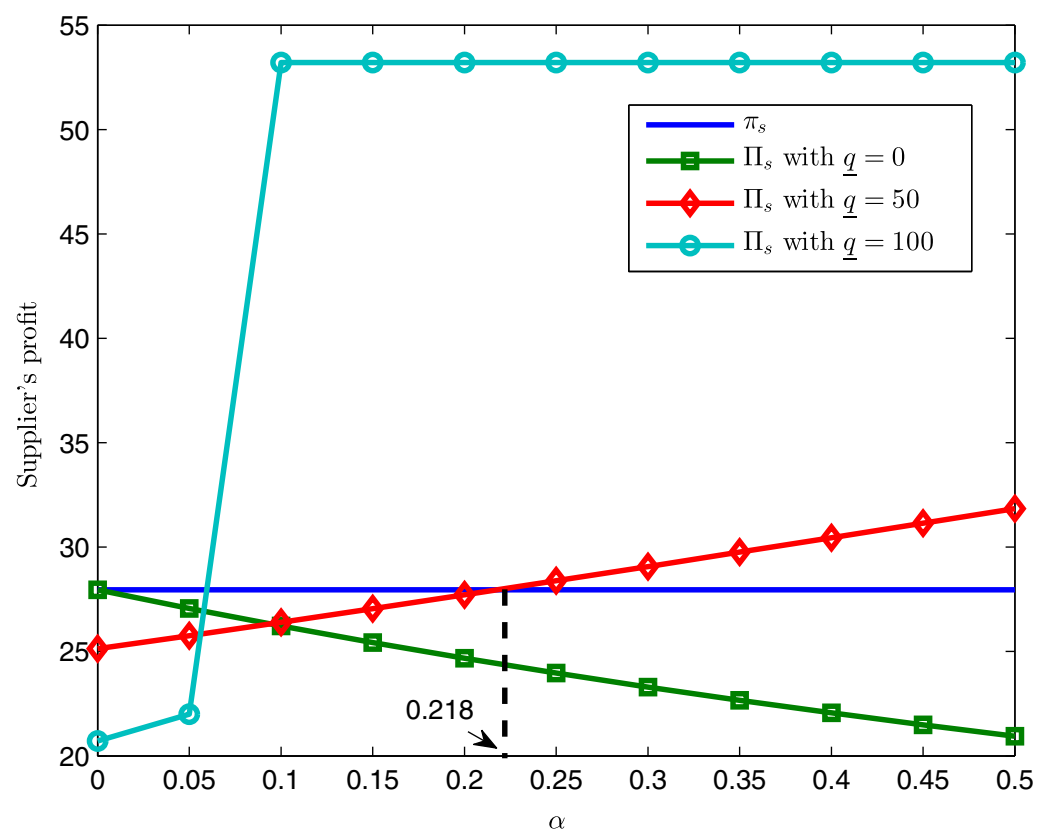

FiguRE 5. The impact of $\alpha$ on the supplier's profit.

retailer with $\alpha \leq 0.235$ (or $\alpha \leq 0.075$ ), thus, when the rebate rate is lower rather than larger than some level, the retailer will prefer new financing policy to traditional bank financing channel.

As shown in Figure 5, the supplier's profit increases with rebate rate $\alpha$ if $q>0$. Compared with the profit under model $\mathrm{T}$, the supplier's profit is less than that under model $\mathrm{T}$, and a larger rebate rate leads to a lower profit of the supplier. Hence, the supplier is willing to set some positive MOQ to guide retailer's ordering. When $\underline{q}=50$ units, the supplier favors new financing policy with the rebate rate $\alpha \geq 0.218$, and larger $\alpha$ is set, more profit the supplier gets. This result is just opposite with the impact of $\alpha$ on retailer's profit. Moreover, with $\underline{q}=100$ units and $\alpha \geq \$ 0.1 /$ units, the supplier gets the largest profit that is identical to the whole supply chain's profit.

Example 2: set the market demand follows an exponential distribution with mean value of 100 units, the cumulative function is $F(x)=1-\exp (-x / 100)$, the product cost per unit $c=\$ 0.1 /$ units. Under model $\mathrm{T}$, the players' optimal decisions are $q_{T}^{*}=78.15 \mathrm{units}, w_{T}^{*}=\$ 0.4577 /$ unit and each party's profit is $\pi_{r}=$ $\$ 18.4581$ and $\pi_{s}=\$ 27.9557$, the integrated supply chain's profit is $\pi_{I}=\$ 46.4139$. Assume the rebate rate $\alpha=\$ 0$ (or $0.3,0.5$ )/units under model $\mathrm{N}$, the impacts of MOQ level $\underline{q}$ on retailer's optimal order quantity and supplier's wholesale price are plotted as Figures 6 and 7, and the impacts of $\underline{q}$ on retailer's profit and supplier's profit are illustrated as Figures 8 and 9 .

Figure 6 shows the impact of $q$ on the retailer's order decision. When the supplier does not offer any rebate rewards to retailer's excess sales $(\alpha=0)$, the retailer's order quantity is increasing with the term of MOQ level, and it is always larger than the order quantity under model T. While if given a positive rebate rate (e.g., $\alpha=0.3$ or 0.5 ), the retailer will be encouraged to make a larger order amount when the MOQ is not less than some threshold (e.g., $q \geq 52$ or 65 ). That is to say, with some certain rebate rate $\alpha$, the supplier should formulate a MOQ level that is higher to some extent, so that the rebate contract will motivate the retailer to make a larger order quantity than her ordering under model T. Thus, the Proposition 4.3 and Corollary 4.4 are verified.

Figure 7 illustrates that if the MOQ does not make retailer's order that is consistent with MOQ, in order to increase retailer's order quantity, the supplier should reduce the wholesale price with increasing the MOQ level. 


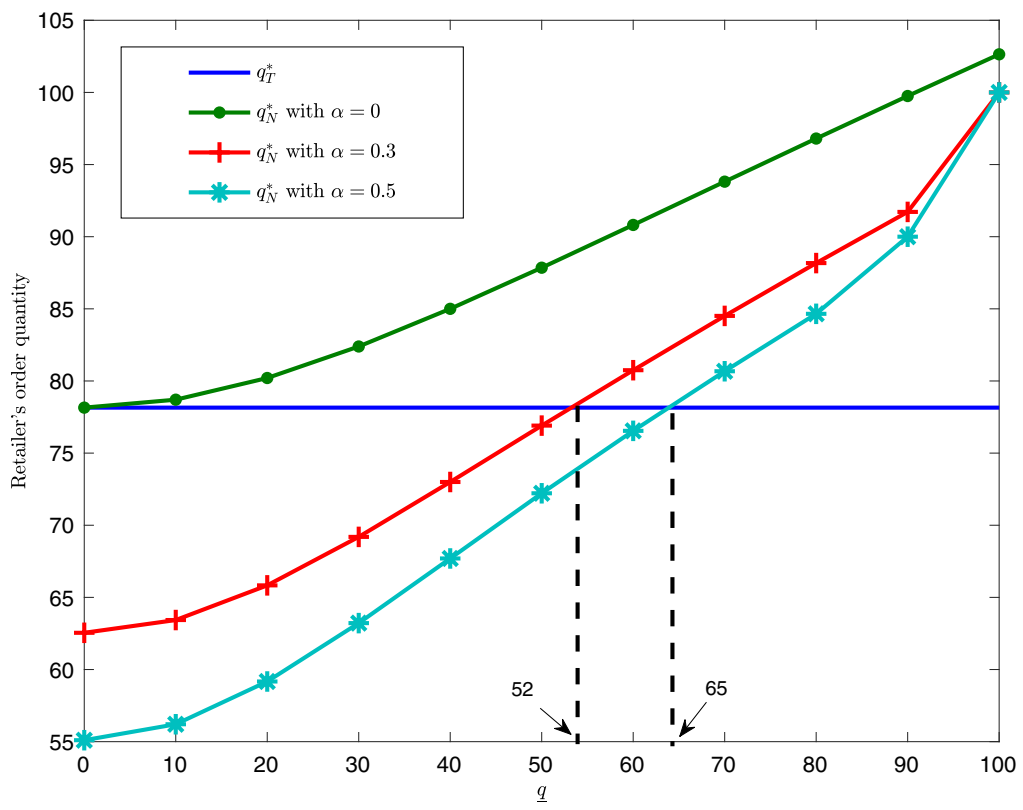

FIGURE 6 . The impact of $\underline{q}$ on the retailer's optimal order quantity.

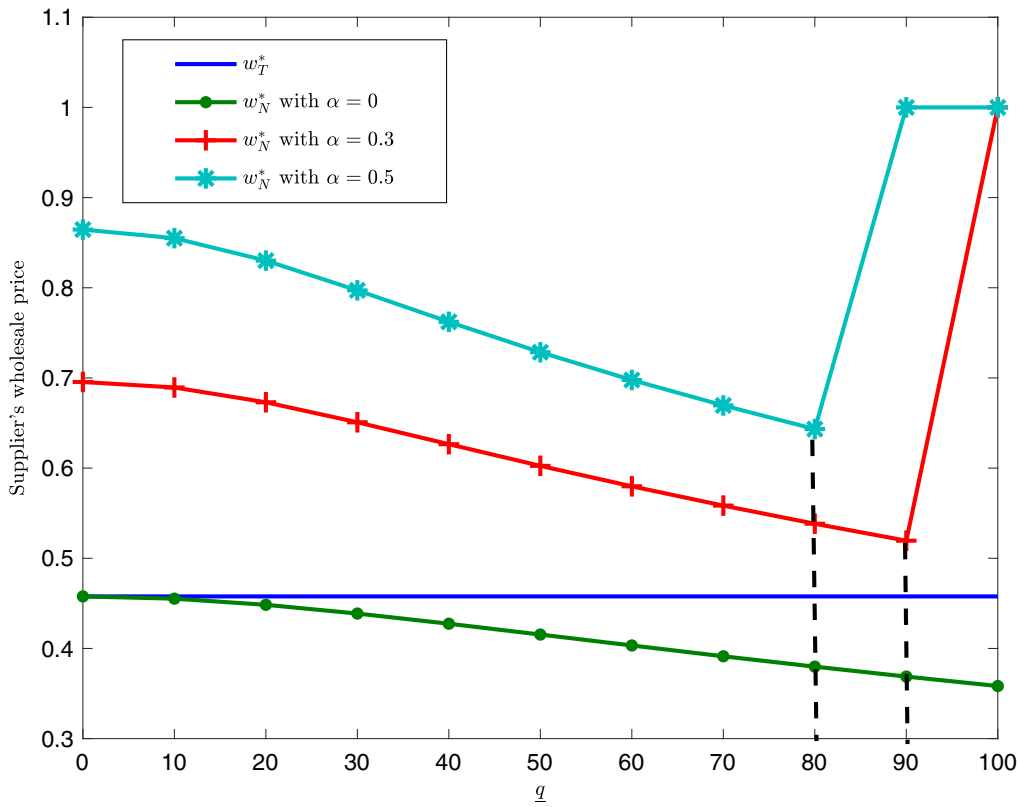

FiguRE 7 . The impact of $q$ on the supplier's wholesale price. 


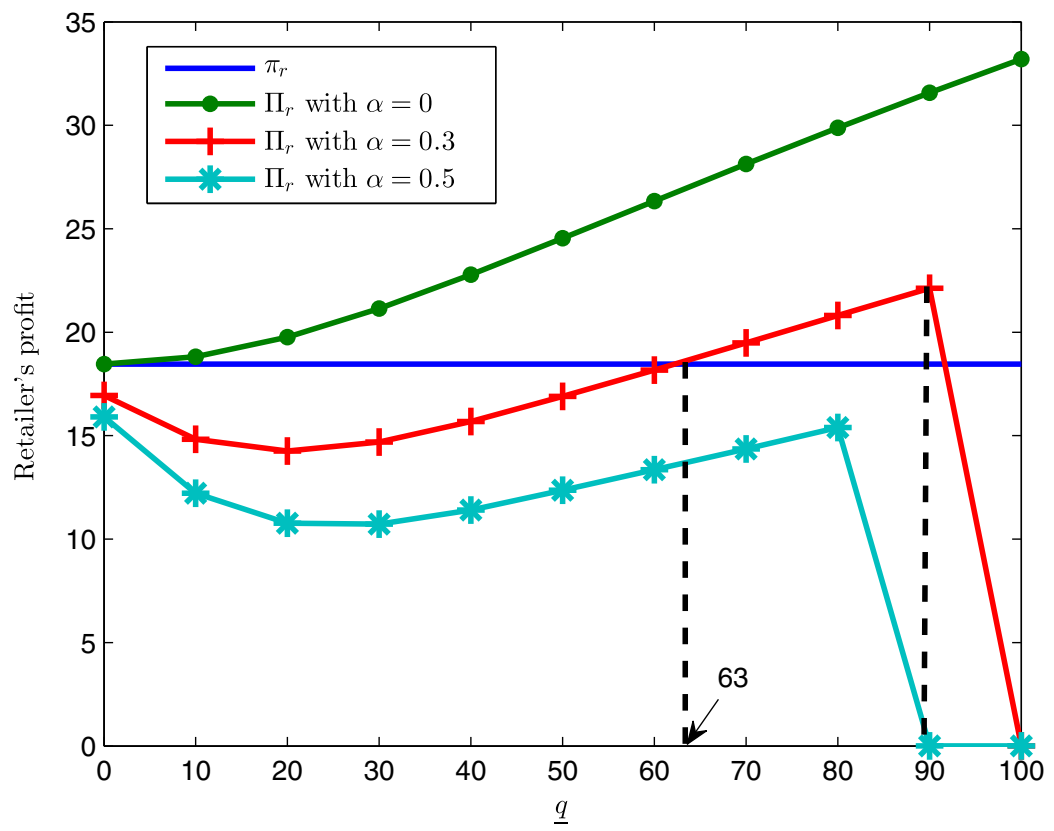

FIGURE 8. The impact of $\underline{q}$ on the retailer's profit.

When the MOQ is larger than some threshold (for example, $q \geq 80$ with $\alpha=0.5$ and $q \geq 90$ with $\alpha=0.3$ ), the retailer is under pressure to enlarge the retailing sales, in this case, the supplier actually sells to consumer by himself. Hence, the wholesale price is just the retailing sales price.

Figure 8 presents how the MOQ level influences the retailer's profit under two financing models. Given a rebate rate $\alpha$, the retailer's profit increases with MOQ level which lies in some extent. When there is none rebate fund from the supplier, the retailer's higher order quantity leads to a larger profit under model N. Suppose that the rebate rate is median (e.g., $\alpha=0.3$ ), the retailer is favorable from the new financing strategy when the MOQ level is neither too lower nor too higher than some threshold (e.g., $63 \leq \underline{q} \leq 90)$, because a much large MOQ level will results in that the retailer gains nothing. However, if the rebate rate $\alpha$ is so high $(e . g ., \alpha=0.5)$ that model $\mathrm{N}$ is inferior to model $\mathrm{T}$ for the retailer. Therefore, Proposition 5.3 is exemplified.

Figure 9 shows the impact of the MOQ level on the supplier's profit, which is consistent with Proposition 5.5. Contrary to the retailer, the supplier gets less profit with a larger $\underline{q}$ when $\alpha=0$. Only with some positive rebate rate and MOQ threshold, the supplier will prefer model $\mathrm{N}$ to model $\mathrm{T}$. For instance, given a rebate rate $\alpha=0.3$, the supplier should regulate the retailer's MOQ to be 27 , and then the model $\mathrm{N}$ precedes model $\mathrm{T}$ for the supplier's profit. If $\alpha=0.5$, the MOQ should be set as 20 and a larger MOQ level leads to a higher profit of the supplier.

The above analysis implies that the rebate contract has an opposite effect on the retailer's profit and the supplier's profit. Some numerical examples are performed to examine whether there exists a Pareto zone of rebate contract that all the players in the supply chain will choose model N simultaneously. Due to the correlation of rebate rate and MOQ, fix some MOQ level and plot the Pareto zone of $\alpha$ for two players' profits under new financing strategy in Figure 10, which shows that given $\underline{q}=60$, the two players' profits and the Pareto zone of $\alpha$ are illustrated in bold line, and the dotted lines characterize the comparisons between two models for each party with $\underline{q}=80$. Figure 10 shows that a higher MOQ is set, a higher rebate rate should be given in the rebate contract, such that both sides of supply chain would like to choose model $\mathrm{N}$ rather than model $\mathrm{T}$. 


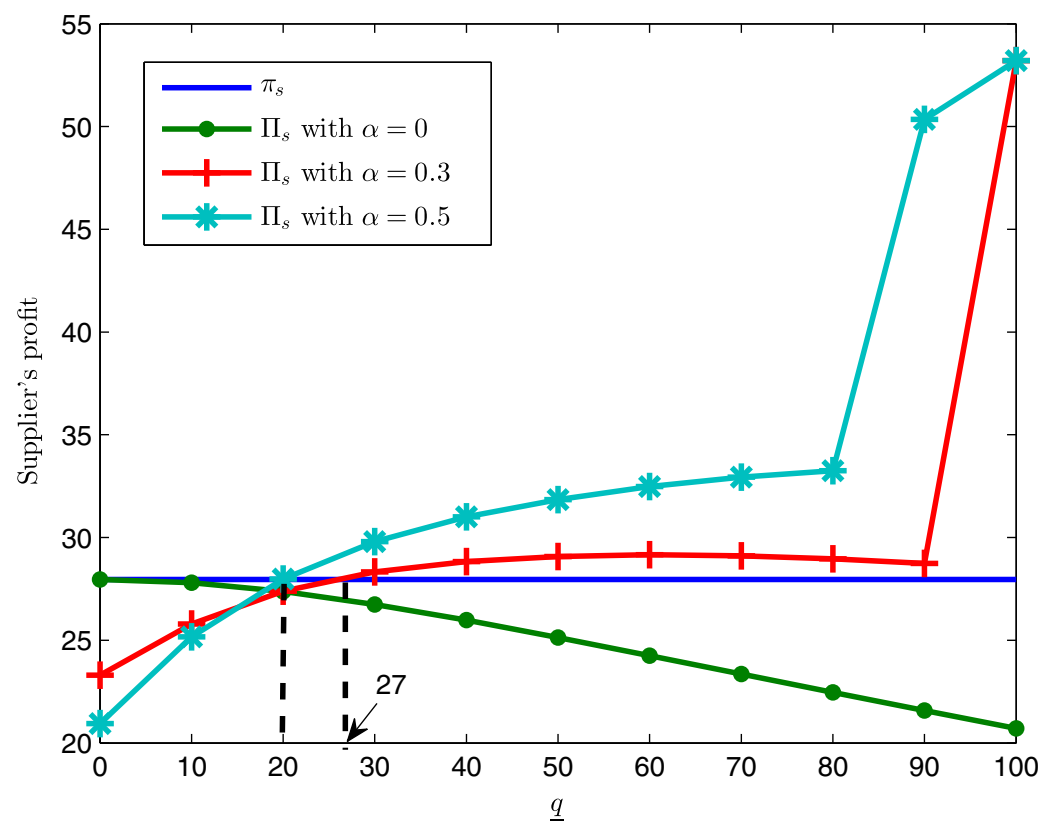

Figure 9. The impact of $q$ on the supplier's profit.

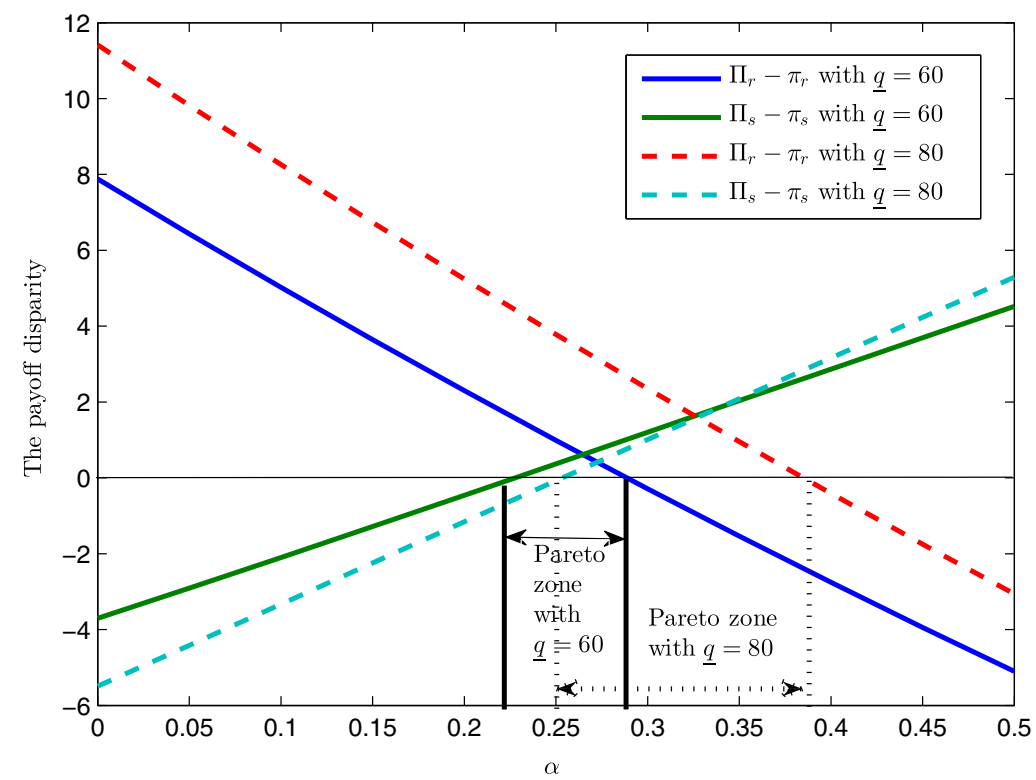

FiguRE 10. The Pareto zone of $\alpha$ where model N outperforms model T for each player's profit. 
TABle 2. The impact of $\underline{q}$ and $c$ on the Pareto zone $[\underline{\alpha}, \bar{\alpha}]$.

\begin{tabular}{llllll}
\hline \hline \multirow{2}{q}{$\underline{q}$} & \multicolumn{5}{c}{$c$} \\
\cline { 2 - 5 } & 0 & 0.05 & 0.10 & 0.15 & 0.20 \\
\hline 50 & - & - & {$[0.218,0.235]$} & {$[0.210,0.248]$} & {$[0.210,0.257]$} \\
60 & - & {$[0.231,0.268]$} & {$[0.228,0.288]$} & {$[0.226,0.305]$} & {$[0.225,0.306]$} \\
70 & {$[0.240,0.288]$} & {$[0.241,0.320]$} & {$[0.241,0.338]$} & {$[0.241,0.347]$} & {$[0.242,0.349]$} \\
80 & {$[0.243,0.337]$} & {$[0.250,0.369]$} & {$[0.253,0.385]$} & {$[0.252,0.355]$} & - \\
90 & {$[0.246,0.388]$} & {$[0.256,0.415]$} & {$[0.267,0.396]$} & - & - \\
100 & {$[0.253,0.432]$} & {$[0.270,0.458]$} & - & - & - \\
\hline
\end{tabular}

Note. "-" represents there exists a null Pareto zone $[\underline{\alpha}, \bar{\alpha}]$ where model $\mathrm{N}$ outperforms model T.

TABLE 3. The impact of $\alpha$ and $c$ on the Pareto zone $\left[\underline{q}_{1}, \underline{q}_{2}\right]$.

\begin{tabular}{llllll}
\hline \hline \multirow{2}{*}{$\alpha$} & \multicolumn{5}{c}{$c$} \\
\cline { 2 - 6 } & 0 & 0.05 & 0.10 & 0.15 & 0.20 \\
\hline 0.20 & - & - & - & {$[42,42]$} & {$[40,47]$} \\
0.25 & {$[63,94]$} & {$[57,82]$} & {$[53,77]$} & {$[51,75]$} & {$[49,72]$} \\
0.30 & {$[73,122]$} & {$[67,102]$} & {$[64,90]$} & {$[60,80]$} & {$[59,73]$} \\
0.35 & {$[83,120]$} & {$[77,103]$} & {$[73,91]$} & {$[71,80]$} & - \\
0.40 & {$[94,118]$} & {$[87,102]$} & {$[84,89]$} & - & - \\
0.45 & {$[104,116]$} & {$[99,101]$} & - & - & - \\
\hline
\end{tabular}

Note. "-" represents there exists a null Pareto zone $\left[\underline{q}_{1}, \underline{q}_{2}\right]$ where model $\mathrm{N}$ outperforms model T.

\subsection{Sensitivity analysis}

Furthermore, this subsection explores the impact of MOQ $q$ and marginal production cost $c$ on the Pareto zone of rebate rate $\alpha$ under equilibrium financing channel. Suppose $c=\$ 0$ (or 0.05, 0.10,0.15,0.20)/units and $\underline{q}=50$ (or $60,70,80,90,100)$ units, the combined effect of $\underline{q}$ and $c$ on the Pareto zone $[\bar{\alpha}, \underline{\alpha}]$ is shown in Table 2 .

Table 2 shows that given a low MOQ (e.g., $q=50$ units) and production cost is not low (e.g., $c \geq \$ 0.1 /$ units), or given a high MOQ (e.g., $q=100$ units) and production cost is not high (e.g., $c \leq \$ 0.05 /$ units), there exists a Pareto zone of $\alpha$ that model $\mathrm{N}$ outperforms model $\mathrm{T}$ for two parties. With the increased $q$ or $c$, the new model $\mathrm{N}$ becomes less superior to traditional model $\mathrm{T}$ for each player in the supply chain. Note that, if the production cost per unit is low, enhancing the MOQ threshold can improve the efficiency of rebate contract during the retailer's bank financing process. Whereas, with increasing production cost, a lower MOQ level will make new model to be superior to traditional model $\mathrm{T}$.

Also, set $c=\$ 0$ (or $0.05,0.10,0.15,0.20) /$ units and $\alpha=\$ 0.20$ (or $0.25,0.30,0.35,0.40,0.45$ )/ units to show the combined impact of $\alpha$ and $c$ on the Pareto zone $\left[\underline{q}_{1}, \underline{q}_{2}\right]$ is illustrated in Table 3 .

Given a rebate rate $\alpha \geq 0.25$, the width of Pareto zone $\left[\underline{q}_{1}, \underline{q}_{2}\right]$ is increasing shorten with production cost $c$, that is, the Pareto zone $\left[\underline{q}_{1}, \underline{q}_{2}\right]$ becomes increasingly narrow. While fixed the marginal production cost $c$, the lower bound of $q$ increases in terms with $\alpha$. Thus, in accordance with a marginal production cost, the supplier can formulate a suitable rebate contract to make model $\mathrm{N}$ precede over model $\mathrm{T}$ for both sides of supply chain. For example, given the marginal production cost $c=0.20$, the rebate contract should includes a rebate rate $\alpha=0.30$ and $59 \leq \underline{q} \leq 73$. Therefore, the evolution of Pareto zone provides some guidances for supplier's decision on setting a rebate contract to create more value under new financing policy for the supply chain. 


\section{Managerial insights}

This paper highlights a new bank financing policy with rebate contract for a capital-constrained retailer under a two-level supply chain. The managerial insights are given as follows:

- Incorporating a given rebate contract into traditional bank financing model could improve the order quantity of supply chain and favors both retailer and supplier.

- Under the bank financing policy with rebate contract, the supplier could not only impel retailer to enhance sales but also provide a part of credit risk warranty to the partner bank.

- Under rebate contract, a higher MOQ level is detrimental to retailer and a larger rebate rate is unprofitable for supplier, therefore, there exists a Pareto zone of rebate contract in which the new model outperforms the traditional model.

- With increasing the marginal production cost, the supplier would reduce the MOQ level or enhance the rebate rate in rebate contract, so that the new financing policy will be superior to traditional financing model in capital-constrained supply chain.

\section{Conclusions And future extensions}

Capital constraints of small-medium retailers could impact the performance of individual and entire supply chain for many industries. Different to the existing literatures on traditional bank credit financing, this paper analyzes a new financing model, in which the supplier offers a rebate contract to the retailer, on one hand, the supplier regulates a MOQ and awards the excess sales to the retailer, on the other hand, the supplier offers a financing risk warranty to the bank if the demand is lower than the MOQ level. Combined a given rebate contract to retailer's bank credit financing, the value of new financing policy to the players is examined in the supply chain.

To investigate the value of new model $\mathrm{N}$, this paper builds a benchmark model $\mathrm{T}$, in which the capitalconstrained retailer is able to borrow capital from traditional bank. When only one financing model is viable, the equilibrium analysis in model $\mathrm{T}$ and model $\mathrm{N}$ are presented respectively. The results show that both the retailer and the supplier have an equilibrium strategy in each model. When two financing model are viable and competitive, the results show that compared to model $\mathrm{T}$, given a suitable rebate contract, model $\mathrm{N}$ will bring a higher ordering quantity to the supply chain, which leads to a higher supply chain profit when the ordering quantity is not too high. This work also shows that there exists a Pareto zone of rebate rate (or MOQ) in the rebate contract in which the model $\mathrm{N}$ outperforms the model $\mathrm{T}$ for all the players. Furthermore, some numerical experiments are performed to inspect how the rebate rate (or MOQ) from the revised rebate contract and the marginal production cost impact on this Pareto zone. The results show that as for a fixed marginal production cost, the rebate contract includes a median rebate rate and a moderate MOQ under model $\mathrm{N}$ will benefit each player and the whole supply chain.

The current study could motivate a number of research directions. First, the capital-constrained retailer's initial budget is assumed to be zero, considering the impact of retailer's own capital on bank financing strategy can be examined in the future (see for instance $[8,26]$ ). Second, the value of this new financing policy can be studied by comparing with other financing models, such as trade credit (see for instance [23, 25]), which will enrich the research of supply chain finance. The numerical analysis is performed from numerical experiments and simulations, an empirical research is worthy of study in the future. Third, the risk-neutral assumption is used in this paper and can be extended by considering risk-averse or risk-seeking makers (see for instance [41]). Last, considering different circumstances in supply chain, such as asymmetric information (see for instance [44]), coordination mechanism (see for instance [38]), multichannel strategy (see for instance [41]), etc. could be future research directions. 


\section{ApPEndix A.}

Proof of Lemma 4.1. From equation (4.2), the bank's profit under model $\mathrm{T}$ can be written as $w_{T} q_{T} r_{T}=$ $\int_{0}^{w_{T} q_{T}\left(1+r_{T}\right)} F(x) \mathrm{d} x$, and substitute into equation (4.1), the retailer's profit is

$$
\pi_{r}=\left(1-w_{T}\right) q_{T}-\int_{0}^{q_{T}} F(x) \mathrm{d} x .
$$

Because $\frac{\partial^{2} \pi_{r}}{\partial q_{T}^{2}}=-f\left(q_{T}\right)<0$, hence, the first induction order condition of equation (4.1) indicates that the retailer's optimal order quantity satisfies $\bar{F}\left(q_{T}^{*}\right)=w$. Substitute $q_{T}^{*}$ into equation (4.3), supplier's profit can be rewritten as $\pi_{s}=\left(\bar{F} q_{T}^{*}-c\right) q_{T}^{*}$, due to the increasing property of generalized function rate $H(x)$, following [8],

$$
\frac{\partial \pi_{s}}{\partial q_{T}^{*}}=\bar{F}\left(q_{T}^{*}\right)\left[1-H\left(q_{T}^{*}\right)\right]-c,
$$

so, $\frac{\partial \pi_{s}}{\partial q_{T}^{*}}$ decreases with $q_{T}^{*}$, so $q_{T}^{*}$ is uniquely solved by $\bar{F}\left(q_{T}^{*}\right)\left[1-H\left(q_{T}^{*}\right)\right]=c$, and the corresponding wholesale price $w_{T}^{*}$ and bank's rate $r_{T}^{*}$ are given as Lemma 4.1 .

Proof of Lemma 4.2. (1) Let $L=\mathbb{E} \min \left[\min \left(D, q_{N}\right)+\alpha\left(\min \left(D, q_{N}\right)-\underline{q}\right)^{+}+\left(w_{N} \underline{q}\left(1+r_{N}\right)-D\right)^{+}\right]$as the expected earnings that the retailer has available at the end of sales season, thus, $L=q_{N}+\alpha\left(q_{N}-\underline{q}\right)-$ $\alpha \int_{\underline{q}}^{q_{N}} F(x) \mathrm{d} x-\int_{w_{N}\left(1+r_{N}\right) \underline{q}}^{q_{N}} F(x) \mathrm{d} x$. In addition, $\Pi_{r} \geq 0$ if and only if $L \geq w_{N} q_{N}$. Following [7], if the retailer's expected profit $\Pi_{r} \geq 0$, then $\widehat{q_{R}}$ is the unique and positive solution to equation (4.6) and $r_{R}^{*}$ is the unique solution to equation (4.8).

(2) First, solve the retailer's optimal order quantity $q_{N}^{*}$ from the first induction order of equation (4.6), that is, $(1+\alpha) \bar{F}\left(q_{N}^{*}\right)=w_{N}$. From equation (4.9),

$$
\Pi_{s}=\left(w_{N}-c\right) q_{N}^{*}-\int_{0}^{w_{N}\left(1+r_{N}\right) \underline{q}} F(x) \mathrm{d} x-\alpha\left[q_{N}^{*}-\underline{q}-\int_{\underline{q}}^{q_{N}^{*}} F(x) \mathrm{d} x\right] .
$$

Then,

$$
\frac{\mathrm{d} \Pi_{s}}{\mathrm{~d} w_{N}}=\left[w_{N}-c-\alpha \bar{F}\left(q_{N}^{*}\right)\right] \frac{\mathrm{d} q_{N}^{*}}{\mathrm{~d} w_{N}}+q_{N}^{*}-\underline{q}\left(1+r_{N}\right) F\left[w_{N}\left(1+r_{N}\right) q\right] .
$$

From $(1+\alpha) \bar{F}\left(q_{N}^{*}\right)=w_{N}$, we have $\frac{\mathrm{d} q_{N}^{*}}{\mathrm{~d} w_{N}}=-\frac{1}{w_{N} h\left(q_{N}^{*}\right)}<0$. While $\left[w_{N}-c-\alpha \bar{F}\left(q_{N}^{*}\right)\right] \frac{\mathrm{d} q_{N}^{*}}{\mathrm{~d} w_{N}}=$ $\left(\frac{c}{w_{N}}-\frac{1}{1+\alpha}\right) \frac{1}{h\left(q_{N}^{*}\right)}$, taking the first order, we have $\left[\left(\frac{c}{w_{N}}-\frac{1}{1+\alpha}\right) \frac{1}{h\left(q_{N}^{*}\right)}\right]_{w_{N}}^{\prime}=-\frac{c}{w_{N}^{2} h\left(q_{N}^{*}\right)}-$ $\frac{w_{N}-c(1+\alpha)}{w_{N}^{2}(1+\alpha)\left(h\left(q_{N}^{*}\right)\right)^{3}} h^{\prime}\left(q_{N}^{*}\right)<0$, also, $-\underline{q}\left(1+r_{N}\right) F\left[w_{N}\left(1+r_{N}\right) \underline{q}\right]$ decreases with $w_{N}$, so $\frac{\mathrm{d} \Pi_{s}}{\mathrm{~d} w_{N}}$ is decreasing with $w_{N}$, and then $\Pi_{s}$ is a concave function of $w_{N}$.

Proof of Proposition 4.3. (1) From equation (4.6), the retailer's order decision is $q_{N}^{*}=\bar{F}^{-1}\left(w_{N} /(1+\alpha)\right)$. Substitute it into equation (4.9), the supplier's optimal wholesale price can be represented as $q_{N}^{*}$. Let $\widehat{q_{N}}$ is solved by

$$
\bar{F}\left(q_{N}\right)\left[1-(1+\alpha) H\left(q_{N}\right)+(1+\alpha)\left(1+r_{N}^{*}\right) h\left(q_{N}\right) \underline{q} F\left(w_{N}^{*}\left(1+r_{N}^{*}\right) \underline{q}\right)\right]=c .
$$

If $\widehat{q_{N}} \geq \underline{q}$, then $q_{N}^{*}=\widehat{q_{N}}$ and the bank's interest rate $r_{N}^{*}$ is the positive root of equation (4.8).

(2) If $\widehat{q_{N}} \leq \underline{q}$, then $q_{N}^{*}=\underline{q}$, so equation (4.8) indicates that $r_{N}^{*}=0$. In this case,

$$
\Pi_{s}=\left(w_{N}-c\right) \underline{q}-\int_{0}^{w_{N} \underline{q}} F(x) \mathrm{d} x .
$$


Thanks that $\left(\Pi_{s}\right)_{w_{N}}^{\prime}=\underline{q} \bar{F}\left(w_{N} \underline{q}\right)>0$, hence $\Pi_{s}$ increases with $w_{N}$, so $w_{N}^{*}=1$ and $q_{N}^{*}=\underline{q}$.

Proof of Corollary 4.4. (1) In the case that $q_{N}^{*}=\widehat{q_{N}}$, let $\Gamma=\bar{F}\left(q_{N}\right)\left[1-(1+\alpha) H\left(q_{N}\right)+(1+\alpha)\right.$ $\left.\left(1+r_{N}^{*}\right) h\left(q_{N}\right) \underline{q} F\left(w_{N}^{*}\left(1+r_{N}^{*}\right) \underline{q}\right)\right]-c=0, q_{N}^{*}$ is the root of $\Gamma$. Taking the derivation of $\alpha$ for both sides of $\Gamma$, we have $\frac{\partial \Gamma}{\partial \alpha}+\frac{\partial \Gamma}{\partial q_{N}^{*}} \frac{\partial q_{N}^{*}}{\partial \alpha}=0$. In which,

$$
\begin{aligned}
\frac{\partial \Gamma}{\partial q_{N}^{*}}= & -c h\left(q_{N}^{*}\right)+\bar{F}\left(q_{N}^{*}\right)\left\{-(1+\alpha) h\left(q_{N}^{*}\right)-(1+\alpha) h^{\prime}\left(q_{N}^{*}\right)\left[q_{N}^{*}-\left(1+r_{N}^{*}\right) \underline{q} F\left(w_{N}^{*}\left(1+r_{N}^{*}\right) \underline{q}\right)\right]\right. \\
& \left.-(1+\alpha)^{2}\left(1+r_{N}^{*}\right)^{2} \underline{q}^{2} h\left(q_{N}^{*}\right) f\left(w_{N}^{*}\left(1+r_{N}^{*}\right) \underline{q}\right) f\left(q_{N}^{*}\right)\right\} \\
\frac{\partial \Gamma}{\partial \alpha}= & \bar{F}\left(q_{N}^{*}\right)\left[-H\left(q_{N}^{*}\right)+\left(1+r_{N}^{*}\right) h\left(q_{N}^{*}\right) \underline{q} F\left(w_{N}^{*}\left(1+r_{N}^{*}\right) \underline{q}\right)\right. \\
& \left.+(1+\alpha)\left(1+r_{N}^{*}\right)^{2} \underline{q}^{2} h\left(q_{N}^{*}\right) f\left(w_{N}^{*}\left(1+r_{N}^{*}\right) \underline{q}\right) \frac{\partial w_{N}^{*}}{\partial \alpha}\right] \\
= & f\left(q_{N}^{*}\right)\left\{-q_{N}^{*}+\left(1+r_{N}^{*}\right) \underline{q}\left[F\left(w_{N}^{*}\left(1+r_{N}^{*}\right) \underline{q}\right)+w_{N}^{*}\left(1+r_{N}^{*}\right) \underline{q} f\left(w_{N}^{*}\left(1+r_{N}^{*}\right) \underline{q}\right)\right]\right\}
\end{aligned}
$$

Furthermore, we prove $1-H\left(q_{N}^{*}\right) \geq 0$ by contradiction. If $1-H\left(q_{N}^{*}\right)<0$, then $1-(1+\alpha) H\left(q_{N}^{*}\right)<0$. Because $\Gamma=0$ holds for all $\underline{q} \geq 0$, therefore, let $\underline{q}=0$ in $\Gamma$, then, $1-(1+\alpha) H\left(q_{N}^{*}\right)=c / \bar{F}\left(q_{N}^{*}\right)>0$, there exists a contradiction. Hence, $1-H\left(q_{N}^{*}\right) \geq 0$.

Due to the increasing property of $H(x), 1-H\left(w_{N}^{*}\left(1+r_{N}^{*}\right) q\right) \geq 0$ implies that $\bar{F}\left(w_{N}^{*}\left(1+r_{N}^{*}\right) q\right) \geq$ $w_{N}^{*}\left(1+r_{N}^{*}\right) \underline{q} f\left(w_{N}^{*}\left(1+r_{N}^{*}\right) \underline{q}\right)$, thus, $\frac{\partial \Gamma}{\partial \alpha} \leq f\left(q_{N}^{*}\right)\left[-q_{N}^{*}+\left(1+r_{N}^{*}\right) \underline{q}\right]$. From equation $(4.8), \underline{q}\left(1+r_{N}^{*}\right) \leq q_{N}^{*}$ is proved as follows:

Case (i) if $\underline{q} \leq w_{N}^{*}\left(1+r_{N}^{*}\right) q_{N}^{*}$, then $w_{N}^{*} q_{N}^{*} r_{N}^{*} \leq\left[\frac{w_{N}^{*} q_{N}^{*}\left(1+r_{N}^{*}\right)+\alpha \underline{q}}{1+\alpha}-w_{N}^{*} \underline{q}\left(1+r_{N}^{*}\right)\right]+$ $\alpha\left[\frac{w_{N}^{*} q_{N}^{*}\left(1+r_{N}^{*}\right)+\alpha \underline{q}}{1+\alpha}-\underline{q}\right]=w_{N}^{*}\left(1+r_{N}^{*}\right)\left(q_{N}^{*}-\underline{q}\right)$, so $\underline{q}\left(1+r_{N}^{*}\right) \leq q_{N}^{*}$.

Case (ii) if $q_{N}^{*} \geq \underline{q} \geq w_{N}^{*}\left(1+r_{N}^{*}\right) q_{N}^{*}$, then $w_{N}^{*} q_{N}^{*} r_{N}^{*}=\int_{w_{N}^{*}\left(1+r_{N}^{*}\right) \underline{q}}^{w_{N}^{*}\left(1+r^{*}\right) q^{*}} F(x) \mathrm{d} x \leq w_{N}^{*}\left(1+r_{N}^{*}\right)\left(q_{N}^{*}-\underline{q}\right)$, so $\underline{q}\left(1+r_{N}^{*}\right) \leq q_{N}^{*}$.

Above all, $\underline{q}\left(1+r_{N}^{*}\right) \leq q_{N}^{*}$, so $\frac{\partial \Gamma}{\partial \alpha} \leq f\left(q_{N}^{*}\right)\left[-q_{N}^{*}+\left(1+r_{N}^{*}\right) \underline{q}\right] \leq 0$. Therefore, $\frac{\partial q_{N}^{*}}{\partial \alpha}=-\frac{\partial \Gamma}{\partial \alpha} / \frac{\partial \Gamma}{\partial q_{N}^{*}} \leq 0$. With the same method, we have $\frac{\partial \Gamma}{\partial \underline{q}} \geq 0$ from $\Gamma$. Thus, $\frac{\partial q_{N}^{*}}{\partial \underline{q}}=-\frac{\partial \Gamma}{\partial \underline{q}} / \frac{\partial \Gamma}{\partial q_{N}^{*}} \geq 0$.

(2) Because $w_{N}^{*}=(1+\alpha) \bar{F}\left(q_{N}^{*}\right)$, so $\frac{\partial w_{N}^{*}}{\partial \underline{q}}=-(1+\alpha) f\left(q_{N}^{*}\right) \frac{\partial q_{N}^{*}}{\partial q} \leq 0$, and $\frac{\partial w_{N}^{*}}{\partial \alpha}=\bar{F}\left(q_{N}^{*}\right)-(1+\alpha) f\left(q_{N}^{*}\right) \frac{\partial q_{N}^{*}}{\partial \alpha} \geq 0$.

Proof of Lemma 5.1. (1) Given $\alpha=0, \widehat{q_{R}^{*}}$ is the root of equation $\bar{F}\left(q_{N}\right)\left[1-H\left(q_{N}\right)+\left(1+r_{N}\right) \underline{q} h\left(q_{N}\right)\right.$ $\left.F\left(w_{N}\left(1+r_{N}\right) \underline{q}\right)\right]=c$. When $\underline{q}=0, q_{N}^{*}=q_{T}^{*}$, and from Corollary 4.4, $q_{N}^{*}$ is increasing with $\underline{q}$, so $q_{N}^{*} \geq q_{T}^{*}$; If $\alpha>0$, then $\left.q_{N}^{*}\right|_{\alpha=0}>q_{T}^{*}$, while $\alpha \geq \frac{1}{\bar{F}\left[\left(1+r_{N}^{*}\right) \underline{q}\right]}-1, \bar{F}\left(q_{N}^{*}\right)\left[1-H\left(q_{N}^{*}\right)\right]=c+$ $\bar{F}\left(q_{N}^{*}\right)\left[\alpha H\left(q_{N}^{*}\right)-(1+\alpha)\left(1+r_{N}^{*}\right) \underline{q} h\left(q_{N}^{*}\right) F\left(w_{N}^{*}\left(1+r_{N}^{*}\right) \underline{q}\right)\right]>c$. Thanks to $\bar{F}(x)[1-H(x)]$ decreases with $x$, thus $q_{N}^{*}<q_{T}^{*}$ with $\alpha \geq \frac{1}{\bar{F}\left[\left(1+r_{N}^{*}\right) \underline{q}\right]}-1$. So, there exists $\underline{\tilde{q}}>0$ such that when $\underline{q}<\underline{\tilde{q}}, q_{N}^{*}<q_{T}^{*}$ and when $\underline{q} \geq \underline{\tilde{q}}, q_{N}^{*} \geq q_{T}^{*}$.

(2) Given $q=0$, then $q_{N}^{*}$ is solved by $\bar{F}\left(q_{N}\right)\left[1-(1+\alpha) H\left(q_{N}\right)\right]=c$. When $\alpha=0, q_{N}^{*}=q_{T}^{*}$, due to $\left(q_{N}^{*}\right)_{\alpha}^{\prime} \leq 0$, so $q_{N}^{*} \leq q_{T}^{*}$. If $q_{N}^{*}=\underline{q}$, then the supplier will set $\underline{q}^{*}=q_{I}>q_{T}^{*}$. If $q_{N}^{*}>\underline{q}>0, q_{N}^{*} \geq q_{T}^{*}$ with $\alpha=0$. When $\alpha \geq \frac{\frac{1}{1}}{1-\left(1+r_{N}^{*}\right) F\left(w_{N}^{*}\left(1+r_{N}^{*}\right) q\right)}-1$, then we have $(1+\alpha)(1+r) F\left(w_{N}^{*}\left(1+r_{N}^{*}\right) \underline{q}\right) \leq \alpha \underline{q} \leq \alpha q_{N}^{*}$, then $-\alpha H\left(q_{N}^{*}\right)+(1+\alpha)(1+r) \underline{q} h\left(q_{N}^{*}\right) F\left(w_{N}^{*}\left(1+r_{N}^{*}\right) \underline{q}\right) \leq 0$, which results in $\widehat{q_{N}} \leq q_{T}^{*}$, so $q_{N}^{*} \leq q_{T}^{*}$. Since $q_{N}^{*}$ decreases with $\alpha$, there exists a $\tilde{\alpha}$, such that $q_{N}^{*} \geq q_{T}^{*}$ with $\alpha \leq \tilde{\alpha}$, while $q_{N}^{*}<q_{T}^{*}$ with $\alpha>\tilde{\alpha}$. 
Proof of Lemma 5.2. Because $w_{N}^{*}=(1+\alpha) \bar{F}\left(q_{N}^{*}\right)$, and $w_{T}^{*}=\bar{F}\left(q_{T}^{*}\right)$, so if $\alpha=0$, we have $q_{N}^{*} \geq q_{T}^{*}$, which indicates that $w_{N}^{*} \leq w_{T}^{*}$. If $\alpha>\tilde{\alpha}>0$ and $q_{N}^{*}>\underline{q}$, then $q_{N}^{*} \leq q_{T}^{*}$, so $w_{N}^{*} \geq w_{T}^{*}$. While if $q_{N}^{*}=\underline{q}$, then $w_{N}^{*}=1>w_{T}^{*}$. In conclusion, if $\alpha>\tilde{\alpha}$, then $w_{N}^{*} \geq w_{T}^{*}$ for all $\underline{q} \geq 0$.

Proof of Proposition 5.3. Compare the retailer's profits under model $\mathrm{N}$ as equation (4.10) and under model T as equation (4.4),

$$
\Pi_{r}=q_{N}^{*} F\left(q_{N}^{*}\right)-\int_{0}^{q_{N}^{*}} F(x) \mathrm{d} x+\alpha\left[q_{N}^{*} F\left(q_{N}^{*}\right)-\underline{q}-\int_{\underline{q}}^{q_{N}^{*}} F(x) \mathrm{d} x\right]+\int_{0}^{w_{N}^{*}\left(1+r_{N}^{*}\right) \underline{q}} F(x) \mathrm{d} x,
$$

and

$$
\pi_{r}=F\left(q_{T}^{*}\right) q_{T}^{*}-\int_{0}^{q_{T}^{*}} F(x) \mathrm{d} x .
$$

(1) If $\alpha \leq \tilde{\alpha}$, then $q_{N}^{*} \geq q_{T}^{*}$, due to $F(x) x-\int_{0}^{x} F(t) \mathrm{d} t$ is increasing with $x$, so $F\left(q_{N}^{*}\right) q_{N}^{*}-\int_{0}^{q_{N}^{*}} F(x) \mathrm{d} x \geq$ $F\left(q_{T}^{*}\right) q_{T}^{*}-\int_{0}^{q_{T}^{*}} F(x) \mathrm{d} x$. So when $X(\alpha, \underline{q})>0, \Pi_{r} \geq \pi_{r}$. If $X(\alpha, \underline{q})<0$ and $\alpha \leq \min (\hat{\alpha}, \tilde{\alpha}), \Pi_{r} \geq \pi_{r}$ is easily to be derived.

(2) If $q_{N}^{*}=\underline{q}$, then suppliers sets the wholesale price $w_{N}^{*}=1$, so $\Pi_{r}=0<\pi_{r}$.

Proof of Corollary 5.4. (1) If $\alpha=0$,

$$
\Pi_{r}=F\left(q_{N}^{*}\right) q_{N}^{*}-\int_{0}^{q_{N}^{*}} F(x) \mathrm{d} x+\int_{0}^{w_{N}^{*}\left(1+r_{N}^{*}\right) \underline{q}} F(x) \mathrm{d} x .
$$

Because $F\left(q_{N}^{*}\right) q_{N}^{*}-\int_{0}^{q_{N}^{*}} F(x) \mathrm{d} x$ is increasing with $q_{N}^{*}$, and $q_{N}^{*} \geq q_{T}^{*}$ with $\alpha=0$, so $\Pi_{r}>\pi_{r}$.

(2) If $\underline{q}=0$, then

$$
\Pi_{r}=F\left(q_{N}^{*}\right) q_{N}^{*}-\int_{0}^{q_{N}^{*}} F(x) \mathrm{d} x+\alpha\left[q_{N}^{*} F\left(q_{N}^{*}\right)-\int_{0}^{q_{N}^{*}} F(x) \mathrm{d} x\right] .
$$

It is obvious that $\Pi_{r}>\pi_{r}$ if and only if $\alpha>\frac{q_{T}^{*} F\left(q_{T}^{*}\right)-\int_{0}^{q_{T}^{*}} F(x) \mathrm{d} x}{q_{N}^{*} F\left(q_{N}^{*}\right)-\int_{0}^{q_{N}^{*}} F(x) \mathrm{d} x}-1$.

Proof of Proposition 5.5. Compare the supplier's profits under model N as equation (4.11) and under model T as equation (4.5), we can rewrite them as

$$
\Pi_{s}=\left(\bar{F}\left(q_{N}^{*}\right)-c\right) q_{N}^{*}-\alpha\left[q_{N}^{*} F\left(q_{N}^{*}\right)-\underline{q}-\int_{\underline{q}}^{q_{N}^{*}} F(x) \mathrm{d} x\right]-\int_{0}^{w_{N}^{*}\left(1+r_{N}^{*}\right) \underline{q}} F(x) \mathrm{d} x,
$$

and

$$
\pi_{s}=\left(\bar{F}\left(q_{T}^{*}\right)-c\right) q_{T}^{*} .
$$

(1) If $q_{N}^{*}>\underline{q}>0$, because $\pi_{s}$ is the optimal profit of $(\bar{F}(x)-c) x$, so $\pi_{s} \geq\left(\bar{F}\left(q_{N}^{*}\right)-c\right) q_{N}^{*}$ with either $q_{N}^{*} \geq q_{T}^{*}$ or $q_{N}^{*}<q_{T}^{*}$. Thus, if $X(\alpha) \geq 0$, then $\Pi_{s} \leq \pi_{s}$ is obvious. While if $X(\alpha)<0, \Pi_{s} \geq \pi_{s}$ if and only if $\alpha \geq \check{\alpha}$.

(2) If $q_{N}^{*}=\underline{q}$, then $w_{N}^{*}=1, r_{N}^{*}=0$. Under this circumstance, equation (4.10) indicates that $\Pi_{r}=0$ and $\Pi_{s}=$ $\Pi_{I}=(1-c) q-\int_{0}^{q} F(x) \mathrm{d} x$. Combined Lemma $5.1, q_{N}^{*}=q \geq q_{T}^{*}$ and $\pi_{I}=(1-c) q_{T}^{*}-\int_{0}^{q_{T}^{*}} F(x) \mathrm{d} x=\pi_{r}+\pi_{s}$, so $\Pi_{I} \geq \pi_{I}$. Combined Proposition 5.3(2), $\pi_{r}>0$, therefore, $\Pi_{s}=\Pi_{I} \geq \pi_{I}>\pi_{s}$. 
Proof of Corollary 5.6. If $\alpha=0$,

$$
\Pi_{s}=\left[\bar{F}\left(q_{N}^{*}\right)-c\right] q_{N}^{*}-\int_{0}^{w_{N}^{*}\left(1+r_{N}^{*}\right) \underline{q}} F(x) \mathrm{d} x .
$$

Because $\left[\bar{F}\left(q_{N}^{*}\right)-c\right] q_{N}^{*} \leq\left[\bar{F}\left(q_{T}^{*}\right)-c\right] q_{T}^{*}$, so $\Pi_{s} \leq \pi_{s}$. And if $\underline{q}=0$, then

$$
\Pi_{s}=\left[\bar{F}\left(q_{N}^{*}\right)-c\right] q_{N}^{*}-\alpha\left[q_{N}^{*} F\left(q_{N}^{*}\right)-\int_{0}^{q_{N}^{*}} F(x) \mathrm{d} x\right] .
$$

Because $\left[q_{N}^{*} F\left(q_{N}^{*}\right)-\int_{0}^{q_{N}^{*}} F(x) \mathrm{d} x\right] \geq 0$ and $\left[\bar{F}\left(q_{N}^{*}\right)-c\right] q_{N}^{*} \leq\left[\bar{F}\left(q_{T}^{*}\right)-c\right] q_{T}^{*}$, so $\Pi_{s} \leq \pi_{s}$.

Proof of Proposition 5.7. The whole supply chain's profit under two finance models are shown in equations (5.1) and (5.2). Lemma 5.1 shows that given a $\underline{q}>0$, if $\alpha \leq \tilde{\alpha}$, then $q_{N}^{*} \geq q_{T}^{*}$. Because the supply chain's profit is increasing in retailer's order quantity, so $\Pi_{I} \geq \pi_{I}$.

Proof of Proposition 5.8. Combined Proposition 5.7, we can see that if $\alpha<\tilde{\alpha}$, then $q_{N}^{*} \geq q_{T}^{*}$ and $\Pi_{I} \geq \pi_{I}$. As for the retailer's profit, Proposition 5.3 shows that $\Pi_{r} \geq \pi_{r}$ if and only if $\alpha<$ $\frac{q_{N}^{*} F\left(q_{N}^{*}\right)-q_{T}^{*} F\left(q_{T}^{*}\right)-\int_{q_{T}^{*}}^{q_{N}^{*}} F(x) \mathrm{d} x+\int_{0}^{w_{N}^{*}\left(1+r_{N}^{*}\right) \underline{q}} F(x) \mathrm{d} x}{\underline{q}-q_{N}^{*} F\left(q_{N}^{*}\right)+\int_{q}^{q_{N}^{*}} F(x) \mathrm{d} x}$, where $U(\alpha)=\underline{q}-q_{N}^{*} F\left(q_{N}^{*}\right)+\int_{\underline{q}}^{q_{N}^{*}} F(x) \mathrm{d} x>0$, that is $\alpha<\bar{\alpha}$. As for the supplier's profit, Proposition 5.5 shows that if $\alpha \geq \check{\alpha}=\underline{\alpha}$, then $\Pi_{s} \geq \pi_{s}$. Therefore, if $\underline{\alpha}<\bar{\alpha}$ and $U(\alpha)>0,[\underline{\alpha}, \bar{\alpha}]$ is the Pareto zone where model $\mathrm{N}$ outperforms model $\mathrm{T}$ for each player in the supply chain.

Acknowledgements. This research is supported by the Natural Science Foundation of China (No. 71502084), Foundation of Philosophy and Social Science Research in Colleges and Universities in Jiangsu Province (No. 2018SJA0325), 2019 Qinglan Project of Jiangsu Province in China, supported by Collaborative Innovation Center of Audit Information Engineering and Technology (No. 18CICA05)

\section{REFERENCES}

[1] Y. Alavi and V. Gaur, Operational investment and capital structure under asset-based lending. Manuf. Serv. Oper. Manage. 20 (2018) 637-654.

[2] S.H. Alavi and A. Jabbarzadeh, Supply chain network design using trade credit and bank credit: a robust optimization model with real world application. Comput. Ind. Eng. 125 (2018) 69-86.

[3] V. Babich, G. Aydin, P.Y. Brunet, J. Keppo and R. Saigal, Risk, Financing and the Optimal Number of Suppliers. Springer, London (2012).

[4] J.A. Buzacott and R.Q. Zhang, Inventory management with asset-based financing. Manage. Sci. 50 (2004) $1274-1292$.

[5] G.P. Cachon and M.A. Lariviere, Supply chain coordination with revenue-sharing contracts: strengths and limitations. Manage. Sci. 51 (2005) 30-44.

[6] G. Cai, X. Chen and Z. Xiao, The role of bank and trade credits: theoretical analysis and empirical evidence. Prod. Oper. Manage. 23 (2014) 583-598.

[7] R. Caldentey and X. Chen, The role of financial services in procurement contracts. In: Handbook of Integrated Risk Management in Global Supply Chains (2010).

[8] X. Chen, A model of trade credit in a capital-constrained distribution channel. Int. J. Prod. Econ. 159 (2015) $347-357$.

[9] X. Chen and A. Wang, Trade credit contract with limited liability in the supply chain with budget constraints. Ann. Oper. Res. 196 (2012) 153-165.

[10] X. Chen, C. Li, B. Rhee and D. Smichi-Levi, The impact of manufacturer rebates on supply chain profits. Nav. Res. Log. $\mathbf{5 4}$ (2007) 667-680.

[11] X. Chen, G. Cai and J. Song, The cash flow advantages of supply chain orchestrators. Manuf. Serv. Oper. Manage. 21 (2018) $435-451$.

[12] C.H. Chiu, T.M. Choi and C.S. Tang, Price, rebate and returns supply chain contracts for coordinating supply chains with price-dependent demands. Prod. Oper. Manage. 20 (2011) 81-91.

[13] S.H. Cho, K.F. McCardle and C.S. Tang, Optimal pricing and rebate strategies in a two-level supply chain. Prod. Oper. Manage. 18 (2009) 426-446. 
[14] M. Dada and Q. Hu, Financing newsvendor inventory. Oper. Res. Lett. 36 (2008) 569-573.

[15] G. Gallego and M. Talebian, Commissions and sales targets under competition. Manage. Sci. 60 (2014) $2180-2197$.

[16] W. Ge and J. Yang, The win-win mechanism on cash management of haier group. Business review (Chinese version). http: //www. ebusinessreview.cn/articledetail-236018.html (2014).

[17] T.S. Genc and P. D. Giovanni, Optimal return and rebate mechanism in a closed-loop supply chain game. Eur. J. Oper. Res. 269 (2018) 661-681.

[18] R. Guchhait, B. Dey, S. Bhuniya, B. Ganguly, B. Mandal, R. Bachar, B. Sarkar, H. Wee and K.S. Chaudhuri, Investment for process quality improvement and setup cost reduction in an imperfect production process with warranty policy and shortages. RAIRO:OR 54 (2020) 251-266.

[19] D. Gupta and L. Wang, A stochastic inventory model with trade credit. Manuf. Serv. Oper. Manage. 11 (2009) 4-18.

[20] A.Y. Ha, W. Shang and Y. Wag, Manufacturer rebate competition in a supply chain with a common retailer. Prod. Oper. Manage. 26 (2017) 2122-2136.

[21] W. Jin, Q. Zhang and J. Luo, Non-collaborative and collaborative financing in a bilateral supply chain with capital constraints. Omegat 88 (2018) 210-222.

[22] B. Jing and A. Seidmann, Finance sourcing in a supply chain. Decis. Support Syst. 58 (2014) 15-20.

[23] B. Jing, X. Chen and G. Cai, Equilibrium financing in a distribution channel with capital constraint. Prod. Oper. Manage. 21 (2012) 1090-1101.

[24] A. Khanna, P. Gautam, B. Sarkar and C. Jaggi, Integrated vendor-buyer strategies for imperfect production systems with maintenance and warranty policy. RAIRO:OR 54 (2020) 435-450.

[25] P. Kouvelis and W. Zhao, Financing the newsvendor: manufacturer vs. bank, and the structurer of optimal trade credit contracts. Oper. Res. 60 (2012) 566-580.

[26] P. Kouvelis and W. Zhao, Supply chain contract design under financial constraints and bankruptcy costs. Manage. Sci. 62 (2016) 2341-2357.

[27] P. Kouvelis and W. Zhao, Who should finance the supply chain? Impact of credit ratings on supply chain decisions. Manuf. Serv. Oper. Manage. 20 (2018) 19-35.

[28] V. Kumar, B. Sarkar, A. Sharma and M. Mittal, New product launching with pricing, free replacement, rework, and warranty policies via genetic algorithm apporach. Int. J. Comput. Intell. Syst. 12 (2019) 519-529.

[29] M.A. Lariviere, A note on probability distribution with increasing generalized failure rates. Oper. Res. 54 (2006) 602-604.

[30] L. Moussawai-Haidar, W. Dbouk, M.Y. Jaber and I.H. Osman, Coordinating a three-level supply chain with delay in payments and a discounted interest rate. Comput. Ind. Eng. 69 (2014) 29-42.

[31] B. Sarkar, An EOQ model with delay in payments and stock dependent demand in the presence of imperfect production. Appl. Math. Comput. 218 (2012) 8295-8308.

[32] B. Sarkar and S. Saren, Product inspection policy for an imperfect production system with inspection errors and warranty cost. Eur. J. Oper. Res. 248 (2016) 263-271.

[33] B. Sarkar, C. Zhang, A. Majumder, Y. Sarkar and Y. Seo, A distribution free newsvendor model with consignment policy and retailer's royalty reduction. Int. J. Prod. Res. 56 (2018) 5025-5044.

[34] B. Sarkar, M. Tayyab, N. Kim and M. Habib, Optimal production delivery policies for suppler and manufacturer in a constrained closed-loop supply chain for returnable transport pack. Comput. Ind. Eng. 135 (2019) 987-1003.

[35] D. Seifert, R.W. Seifert and M. Protopappa-Sieke, A review of trade credit literature: opportunities for research in operations. Eur. J. Oper. Res. 231 (2013) 245-256.

[36] T. Taylor, Supply chain coordination under channel rebates with sales effort effects. Manage. Sci. 48 (2002) $992-1007$.

[37] P. Vandenberg, Adapting to the financial landscape: evidence from small firms in Nairobi. World Dev. 31 (2003) $1829-1843$.

[38] W.K. Wong, J. Qi and S.Y.S. Leung, Coordinating supply chains with sales rebate contracts and vendor-managed inventory. Int. J. Prod. Econ. 120 (2009) 151-161.

[39] X. Xu and J. Birge, Operational decisions, capital structure and managerial compensation: a newsvendor perspective. Eng. Econ. 53 (2008) 173-196.

[40] N. Yan, B. Sun, H. Zhang and C. Liu, A partial credit guarantee contract in a capital-constrained supply chain: financing equilibrium and coordinating strategy. Int. J. Prod. Econ. 173 (2016) 122-133.

[41] N. Yan, X. He and Y. Liu, Financing the capital-constrained supply chain with loss aversion: supplier finance vs. supplier investment. Omega 88 (2019) 162-178.

[42] A. Yang, J. Birge and R. Parker, The supply chain effects of bankruptcy. Manage. Sci. 61 (2015) $2320-2338$.

[43] J. Zhou and H. Groenevelt, Impacts of financial collaboration in a three-party supply chain. Working paper, The Simon School, University of Rochester, NY (2007).

[44] J. Zhou, R. Zhao and W. Wang, Pricing decision of a manufacturer in a dual-channel supply chain with asymmetric information. Eur. J. Oper. Res. 278 (2019) 809-820. 